\title{
Failed, Interrupted, or Inconclusive Trials on Immunomodulatory Treatment Strategies in Multiple Sclerosis: Update 2015-2020
}

\author{
Leoni Rolfes ${ }^{1}$ - $\cdot$ Marc Pawlitzki $^{1}$ - Steffen Pfeuffer ${ }^{1}$. Niklas Huntemann ${ }^{1} \cdot$ Heinz Wiendl ${ }^{1} \cdot$ Tobias Ruck $^{1}$. \\ Sven G. Meuth ${ }^{1}$
}

Published online: 12 August 2020

(c) The Author(s) 2020

\begin{abstract}
In the past decades, multiple sclerosis (MS) treatment has experienced vast changes resulting from major advances in disease-modifying therapies (DMT). Looking at the overall number of studies, investigations with therapeutic advantages and encouraging results are exceeded by studies of promising compounds that failed due to either negative or inconclusive results or have been interrupted for other reasons. Importantly, these failed clinical trials are informative experiments that can help us to understand the pathophysiological mechanisms underlying MS. In several trials, concepts taken from experimental models were not translatable to humans, although they did not lack a well-considered pathophysiological rationale. The lessons learned from these discrepancies may benefit future studies and reduce the risks for patients. This review summarizes trials on MS since 2015 that have either failed or have been interrupted for various reasons. We identify potential causes of failure or inconclusiveness, looking at the path from basic animal experiments to clinical trials, and discuss the implications for our current view on MS pathogenesis, clinical practice, and future study designs. We focus on anti-inflammatory treatment strategies, without including studies on already approved and effective DMT. Clinical trials addressing neuroprotective and alternative treatment strategies are presented in a separate article.
\end{abstract}

Tobias Ruck and Sven G. Meuth contributed equally.

Leoni Rolfes

leoni.rolfes@ukmuenster.de

Marc Pawlitzki

marc.pawlitzki@ukmuenster.de

Steffen Pfeuffer

steffen.pfeuffer@ukmuenster.de

Niklas Huntemann

niklas.huntemann@ukmuenster.de

Heinz Wiendl

heinz.wiendl@ukmuenster.de

Tobias Ruck

tobias.ruck@ukmuenster.de

Sven G. Meuth

sven.meuth@ukmuenster.de

1 Department of Neurology With Institute of Translational

Neurology, University Hospital Muenster,

Albert-Schweitzer-Campus 1, 48149 Münster, Germany

\section{Key Points}

Failed or inconclusive multiple sclerosis (MS) trials are invaluable to our understanding of the pathophysiology and treatment of MS.

Trial failure present in relapsing-remitting study populations unveiled, among other things, the complexity of B-cell involvement in MS pathophysiology, that higher selectivity can probably imply lower efficacy, and that current animal models are useful tools but are not able to completely mimic the complexity of human disease.

Trial failures in patient populations with progressive forms of MS indicate that the best placement of future trials is in the early and more active phases of the progressive disease. Careful selection of study duration and outcome parameters, with a focus on longer follow-up periods and shorter tract-based pathway functions might be critical to a successful outcome. 


\section{Introduction}

The past decade has been marked by an overall decrease in the successful development of new drugs. Clinical trials in multiple sclerosis (MS) are regarded as an exception to this trend [1]. In this context, MS trials have a $27 \%$ success rate, defined as passing phases I, II, and III and receiving approval from the United States Food and Drug Administration (FDA) or European Medicines Agency (EMA), almost tripling the average industry rate of $10 \%$ [1]. Therapeutic options for patients with MS have developed from solely steroids to 13 approved diseasemodifying therapies (DMT), ranging from injectable biologics to the more recently approved small molecule drugs [2]. In addition, the methodology employed in MS trials has evolved in parallel with the therapeutic agents; for example, utilizing magnetic resonance imaging (MRI) techniques as a 'surrogate marker' to assess potential drug effects and biomarkers [3, 4].

Since inflammatory events are central to MS disease development, recent treatment approaches particularly reduce inflammatory disease activity $[5,6]$ by blocking the trafficking of autoreactive lymphocytes [7], preventing their adhesion and penetration into the central nervous system (CNS) [8], depleting their number, or targeting local activation and proliferation [9-11]. Novel emerging therapies are sophisticated monoclonal antibody (mAb) approaches and small molecule drugs based on a growing understanding of the underlying molecular signatures and immunopathophysiology of MS [12, 13].

Although the advances in DMT development for MS are encouraging, most drugs primarily target the immune system, aiding patients with relapsing-remitting MS (RRMS), while therapeutics indicated for progressive formsnamely secondary progressive MS (SPMS) and primary progressive MS (PPMS) — are sparse. The repurposing of drugs has been widely performed to establish a more effective and less expensive strategy [14]. However, agents used effectively in other autoimmune diseases or showing efficacy in one particular form of MS do not necessarily target all MS subtypes [7, 8, 15, 16]. In fact, despite rational therapeutic concepts and convincing preliminary results from animal experiments, numerous promising candidates failed in clinical studies. Finally, despite their effectiveness, several agents have revealed unexpected safety issues and risks during long-term treatment, leading to approval restrictions or withdrawal [17-19].

While trials with positive outcomes are usually published in prestigious journals, many negative results are merely published as abstracts or not at all. It is, however, highly important to critically reflect on (unexpected) negative results to optimize future study designs and provide crucial insights into the immunopathogenesis of MS [18].

This article will discuss therapeutic strategies tested in phase I-III clinical trials in various MS subtypes since 2015, where either the therapy was ineffective, or the study was halted. We analyze the reasons underlying failure and discuss the implications for our current view on MS pathogenesis, clinical practice, and future study designs.

\section{Methods}

We conducted a MEDLINE search to identify relevant articles published between 01 January 2015 and 31 December 2019. The Medical Subject Headings (MeSH) terms applied were 'multiple sclerosis', 'therapy' or 'treatment', and 'trial'. Since failed trials are often not published in peer-reviewed journals, eligible studies were also sourced from international conferences, namely the Annual Meeting-American Academy of Neurology (AAN) and the European/Americas Committee for Treatment and Research in Multiple Sclerosis (ECTRIMS/ACTRIMS), personal communications with the authors, and consultation of national and international registries for clinical trials [United States National Library of Medicine (NLM); clinicaltrials.gov; European Union Drug Regulating Authorities Clinical Trials Database (EudraCT)].

Clinical trials for drugs that were intended to treat secondary complications of MS, such as spasticity, fatigue, and cognitive impairment, were excluded. Drugs being tested in combination with other drugs were included as long as the other drug was already FDA/EMA approved to treat MS.

\subsection{Classification of Clinical Trial Failure}

A compound was deemed a clinical failure if it failed to meet the primary study endpoint (pSE). A short and incomplete overview will be provided concerning 'commercial' failures, meaning a compound that met the primary endpoint but failed to progress to a subsequent clinical trial because of the pharmaceutical company's decisions.

The MEDLINE search with the outlined MeSH terms, together with studies presented at conferences and listed on clinicaltrials.gov, returned 6656 records in total. Amongst these studies, 21 records with a total of 16 distinct compounds met our inclusion criteria (for details on the search strategy see Fig. 1; for details on individual compounds see Table 1).

\section{Failed Clinical Trials in Relapsing- Remitting Multiple Sclerosis}

\subsection{B-Cell Targeting Therapies}

Traditionally considered a T-cell-mediated disorder, the contribution of $\mathrm{B}$ cells in MS pathogenesis is now widely accepted [12, 20-24]. Compelling evidence for the 


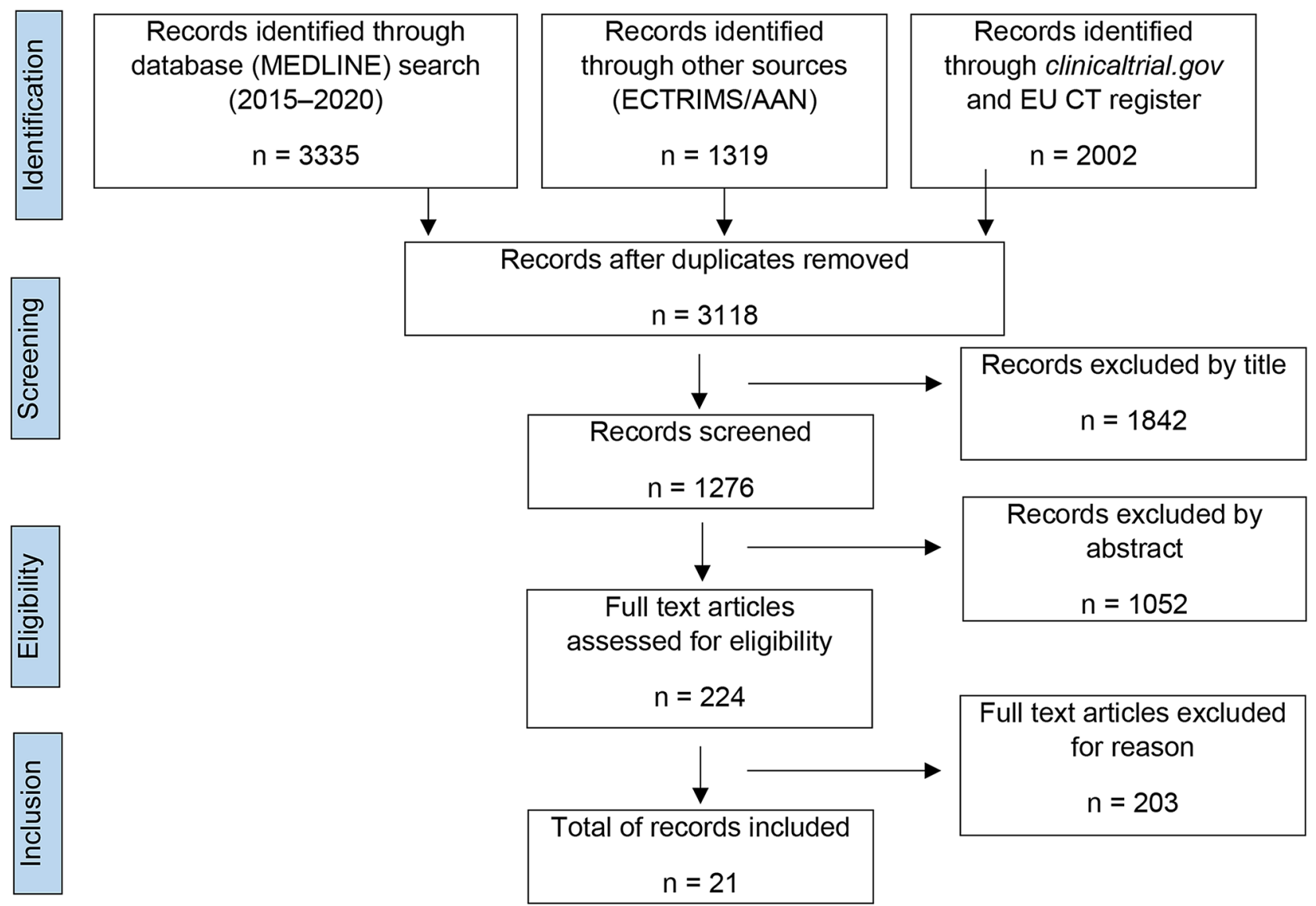

Fig. 1 PRISMA flow diagram of the reviewed literature. AAN American Academy of Neurology, ECTRIMS European Committee for Treatment and Research in Multiple Sclerosis, EU CT register European Union Clinical Trials register

involvement of B cells include immunoglobulin and complement deposits in demyelinating brain lesions, the presence of intrathecal immunoglobulin synthesis, and, most importantly, striking results from clinical trials on B-cell depletion therapies [12, 20-22]. Multiple strategies have been proposed for modulating B-cell populations in MS patients, including chimeric, humanized, and human $\mathrm{CD} 19^{+}$(inebilizumab) and $\mathrm{CD}_{2} 0^{+}$(rituximab, ocrelizumab, and ofatumumab) $\mathrm{mAb}$, and agents (atacicept and tabalumab) that target B-cell maturation and differentiation [16, 25-28].

\subsubsection{Atacicept (TACl-lgG)}

3.1.1.1 Background Based on the promising effects of B-cell-depleting therapies, it was reasonably argued that the modulation of B-cell differentiation, maturation, and survival could also provide therapeutic benefit. B-cell maturation and differentiation depend on co-stimulatory signals and cannot be triggered by stimulation of the B-cell receptor alone. The B-cell survival factors BAFF/BlyS (BAFF$\mathrm{R} / \mathrm{TNFSR} 13 \mathrm{~B} / \mathrm{CD} 268$ ) and a proliferation-inducing ligand
(APRIL/TNFSF13/CD256) are central co-stimulatory factors for B cells. BAFF binds to and acts via the transmembrane activator, calcium modulator, and cyclophilin ligand interactor (TACI/TNFSR13C/CD267) receptor, the $\mathrm{BAFF}$ receptor, and the $\mathrm{B}$-cell maturation antigen (BCMA/ TNFSR17/CD269). The BCMA receptor is also bound by APRIL (see, e.g., Schneider et al. for a detailed review on this topic [29]).

Atacicept is a human recombinant fusion protein and consists of the extracellular ligand-binding portion of the human TACI receptor, linked to a recombinant Fc domain of human IgG. It binds to soluble BAFF/BLyS and APRIL molecules and targets those factors via sequestration or neutralization, thereby preferentially impairing mature B cells and plasma cells, with less impact on progenitor and memory subsets [30, 31]. Since both compounds rely on the same mechanism, results from atacicept trials will be discussed together with results obtained from trials on tabalumab, a fully human IgG4 monoclonal antibody that neutralizes membrane-bound and soluble BAFF. 


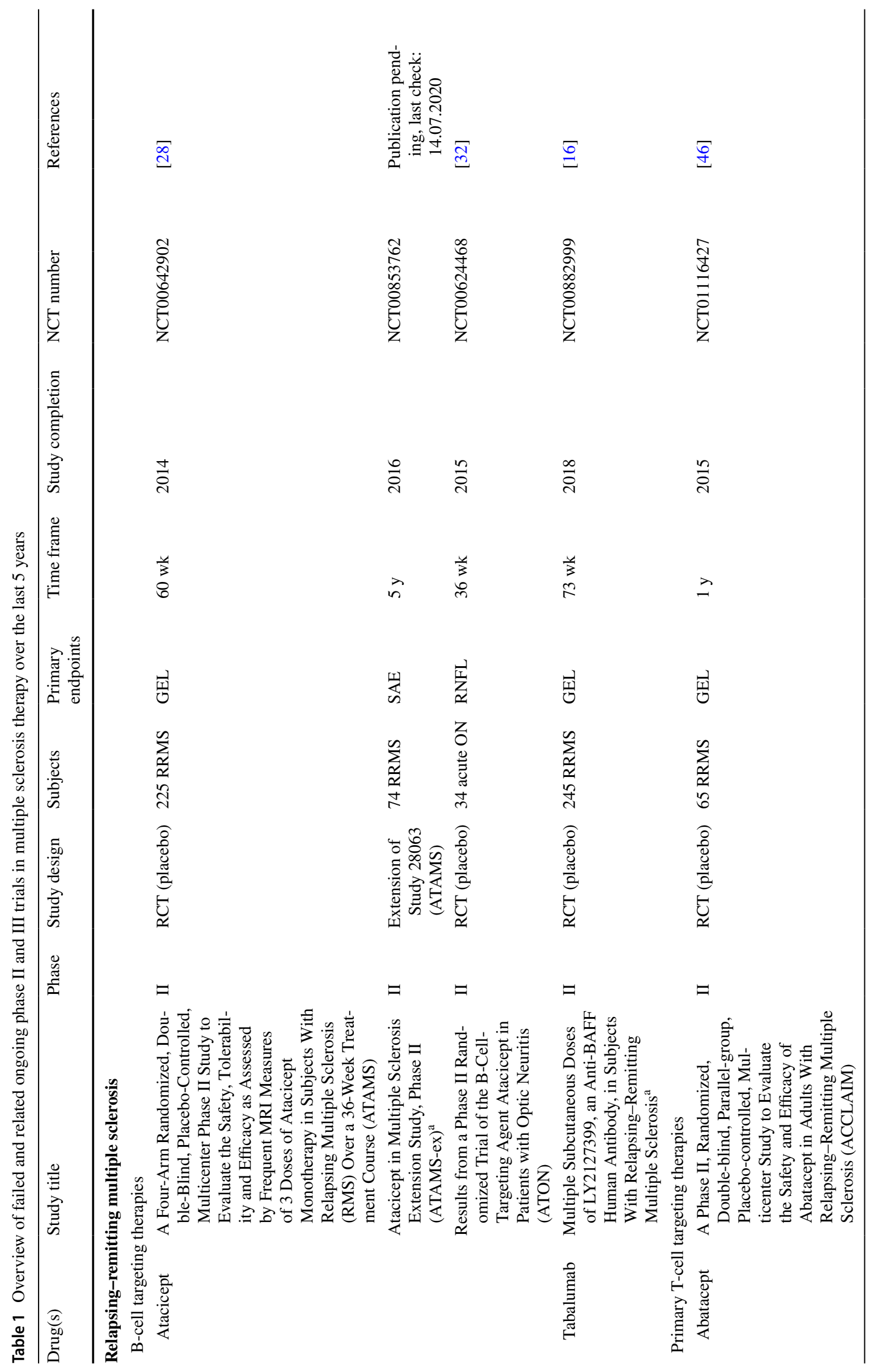




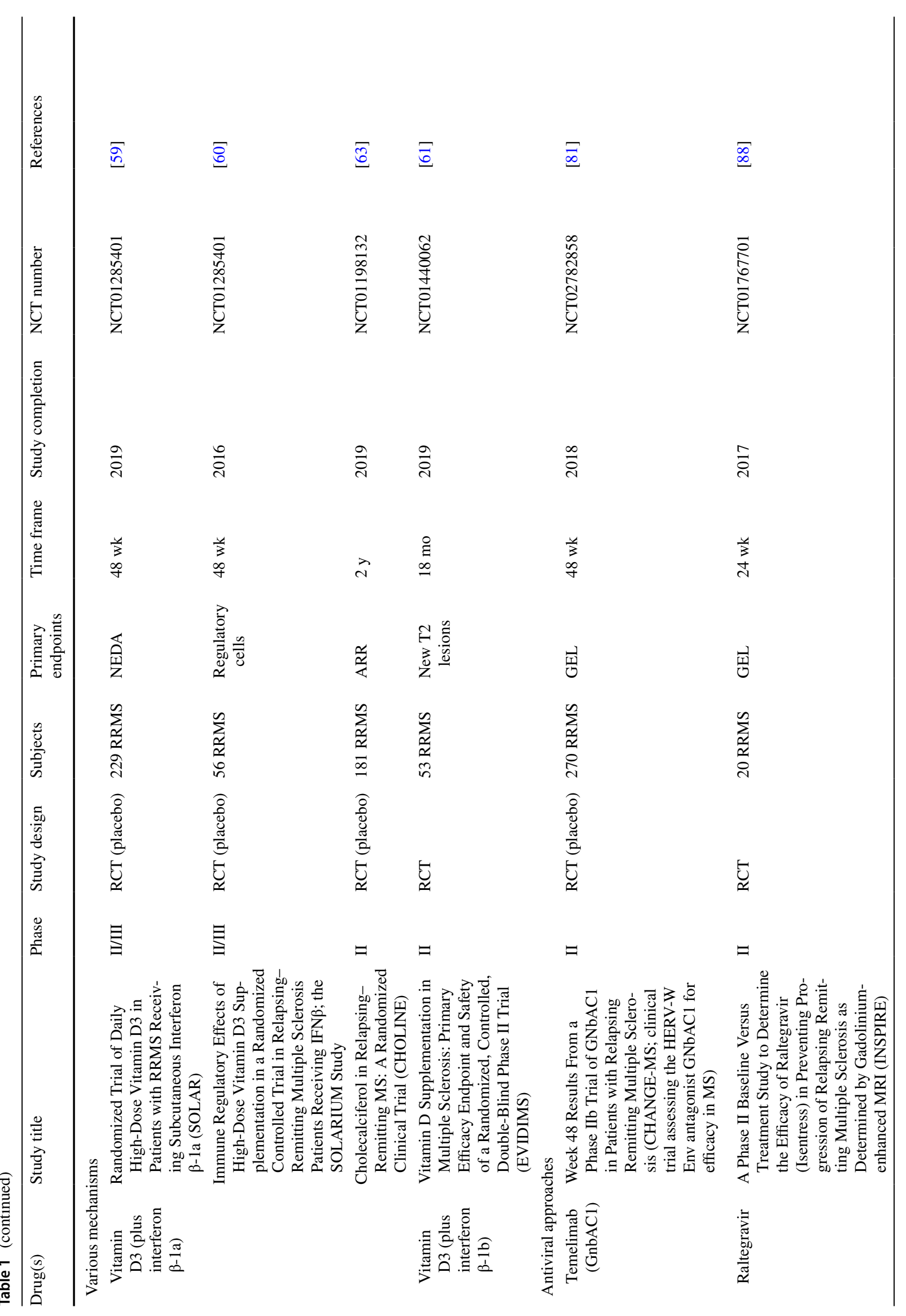




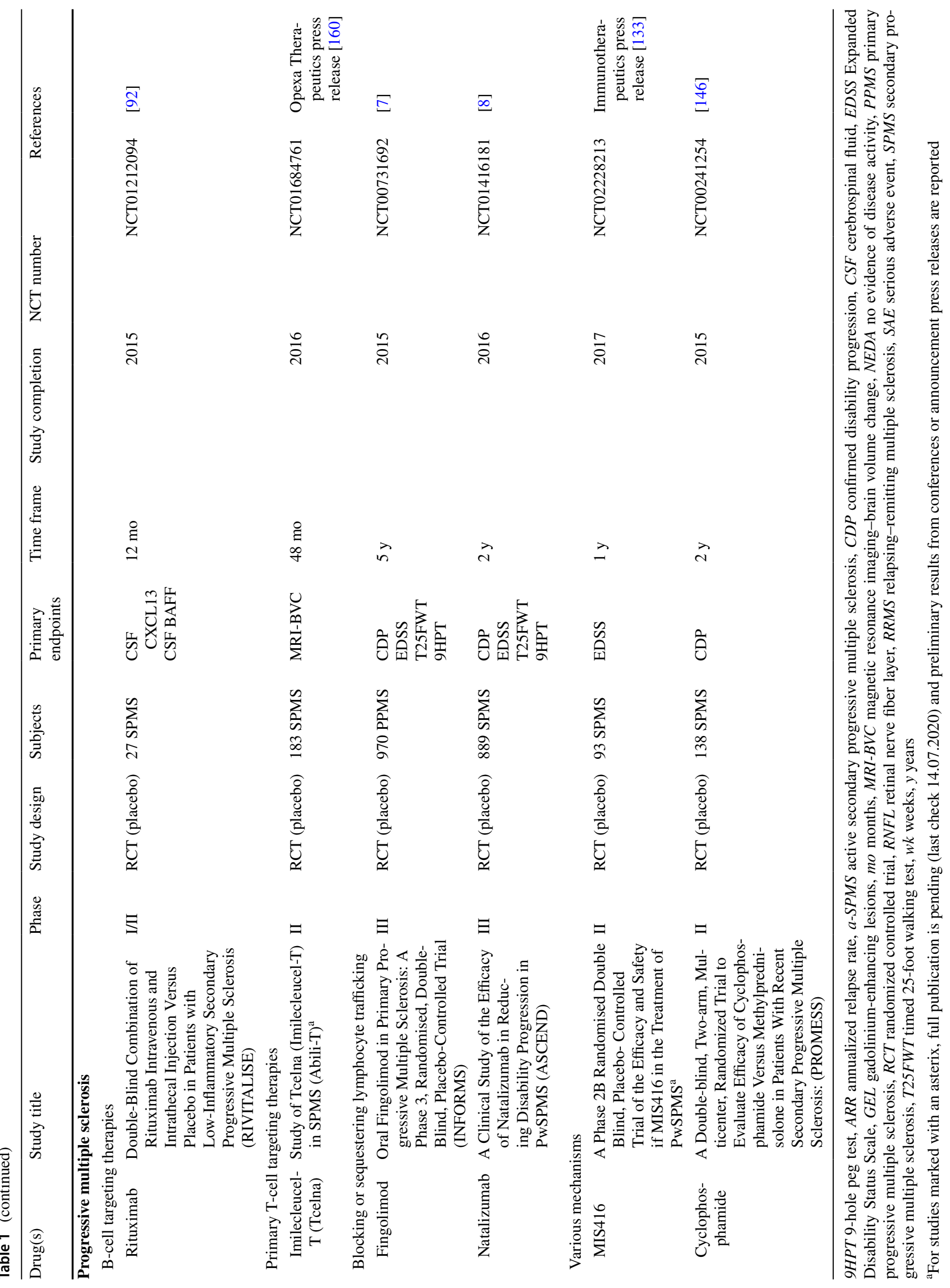


3.1.1.2 Studies So far, two phase II studies (ATAMS and ATON) and a related extension trial (ATAMS-ex, NCT00853762) have been conducted in patients with either RRMS (ATAMS and ATAMS-ex) or acute optic neuritis (ON; ATON) [28, 32]. In the ATAMS study, 225 patients with RRMS were included and received weekly subcutaneous injections of atacicept $(25,75$, or $150 \mathrm{mg})$ or placebo for 36 weeks, with the possibility of open-label extension to reach a total treatment period of up to 5 years (ATAMS-ex). Notably, after the independent monitoring and safety board observed increased MS disease activity, with the annualized relapse rate (ARR) more than double in all atacicept groups compared with placebo, the ATAMS trial was prematurely terminated. The relapse rate was initially a tertiary outcome in the trial and did not affect the primary outcome-mean number of gadolinium-enhanced lesions (GEL) in brain MRI—or long-term disease progression assessed via a 60-week safety follow-up during which patients received standard DMT to reduce disease activity.

The 36-week ATON study compared the efficacy and safety of atacicept against placebo in 34 patients with ON as the first demyelinating event [32]. The pSE was the change in retinal nerve fiber layer thickness (RNFL) as a marker for optic nerve integrity measured by optical coherence tomography. The study was canceled after the ATAMS study showed negative results. Analysis of the prematurely terminated study showed a lesser decrease in RNFL in the atacicept treatment group. However, in the atacicept treatment group, a higher proportion of patients converted to clinically definite MS compared with placebo.

\subsubsection{Tabalumab}

3.1.2.1 Studies Silk and Nantz reported on a phase II, dose-escalating, randomized, placebo-controlled study evaluating the efficacy and safety of tabalumab in 245 patients with RRMS [16]. Participants either received tabalumab or placebo subcutaneously for a study duration of 73 weeks. The pSE was the number of total cumulative GEL (whether new, pre-existing, unchanged, or enlarged from previous scans), averaged over weeks 12-24. The study failed to meet the pSE, as no differences were detected between any of the tabalumab groups and placebo. Furthermore, there was no indication of any treatment effect on secondary outcomes, including the difference in the development of new and enlarging T2 lesions or the ARR. Notably, there was no evidence for rising numbers of relapses following tabalumab treatment, contrasting with the results from the atacicept trial. However, the proportion of patients reporting at least one treatment-emergent adverse event and the number of serious adverse events was higher in tabalumabexposed patients compared with placebo (results currently not further specified). Full publication of this failed trial is still pending.

3.1.2.2 Comment Clinical studies on atacicept and tabalumab highlight the complexity of B-cell-related immune responses in $\mathrm{MS}$ and explore the underlying mechanisms since anti-CD20 drugs showed benefits in previous trials. In contrast to anti-CD20 antibodies, atacicept inhibits the differentiation of B cells into plasma cells and lowers serum immunoglobulin levels, while leading to an accumulation of transitional B cells rather than depleting them [28, 33]. Plasma cell depletion may have led to positive treatment effects in other autoimmune diseases [e.g., rheumatoid arthritis (RA)] that are strongly linked to autoantibody production [34]. In MS, antibodies themselves may also play a role; however, the regulation of $\mathrm{T}$ cells via B-celldependent mechanisms seems more important [12]. In the pathogenesis of MS, a divergent role for B cells has been described. On the one hand, antigen-specific B cells can provide the essential stimulus for antigen-specific $\mathrm{T}$ cells. On the other hand, interleukin (IL)-10-producing B cells can have a regulatory effect, constraining the activation of $\mathrm{T}$ cells and thereby reducing disease severity [35]. Indeed, BAFF/BLyS are essentially involved in the differentiation of these regulatory B cells [36]. Thus, one possible explanation for increased disease activity, as seen in ATAMS, might be the B-cell subset-specific effects of atacicept, disturbing the fine-tuned balance of conventional and regulatory B cells and resulting in exaggerated T-cell responses.

Moreover, atacicept and tabalumab transiently increase memory B cells $[16,37]$. Therefore, probably the most important issue is that, compared with other B-cell targets such as $\mathrm{CD} 20^{+}$cells, memory $\mathrm{B}$ cells are spared under treatment with both tabalumab and atacicept, and T-cell activation may be preserved [28].

Furthermore, a direct mechanistic comparison of the small molecule atacicept with the mAb tabalumab would be of interest. Unfortunately, final publication of the failed trial of tabalumab is still pending, such that no conclusions about the differences in shifting B-cell populations can be provided so far. Additionally, the final results of the ATAMS-ex study are of particular interest but are also still pending. Whether long-term disease progression, including conversion to the SPMS subtype, and safety profile will differ in the atacicept compared with the placebo group is therefore currently not clear.

Another human mAb-targeting BAFF, Ianalumab (VAY736), was recently tested in a phase II trial (NCT02038049). However, the study recruitment was terminated based on strategic considerations after the enrolment of eight patients. The results of this trial are not available yet. 


\subsection{Primary T-Cell Targeting Therapies}

The pathophysiological rationale for targeting $\mathrm{T}$ cells in MS is based on several aspects, including the accumulation of considerable numbers of both $\mathrm{CD} 4^{+}$and $\mathrm{CD} 8^{+}$cells in inflammatory MS lesions [38]. Also, data from different genome-wide susceptibility studies revealed that most MSrelated genes are involved in antigen presentation to $\mathrm{T}$ cells or affect the T-cell pathways themselves [39]. Several of the currently approved DMT for treating MS target T lymphocytes, either in a pleiotropic manner (e.g., interferons), by depleting immune cell populations involving $\mathrm{T}$ cells (e.g., anti-CD52, alemtuzumab), or by directly interfering with specific pathways (e.g., natalizumab).

\subsubsection{Abatacept}

3.2.1.1 Background Cytotoxic T-lymphocyte-associated protein 4 (CTLA-4; CD152) is an extensively studied coinhibitory molecule expressed on $\mathrm{T}$ lymphocytes, dampening immune responses upon binding to B7-1 (CD80) or B7-2 (CD86) on antigen-presenting cells. CTLA-4 is known to be an important negative regulator of T-cell function [40]. Further, CTLA-4 has been implicated in the control of self-reactivity by modulating the action of $\mathrm{CD} 4{ }^{+} \mathrm{CD} 25^{+}$ regulatory T cells (Treg) [41]. In this context, anti-CTLA-4 treatment exacerbated the disease course in an experimental autoimmune encephalomyelitis (EAE) model, while certain CTLA-4 gene polymorphisms also seem to be associated with human MS [42, 43]. The CTLA-4 pathway can be activated by abatacept, a chimeric protein consisting of the extracellular domain of human CTLA-4 fused to the Fc region of human IgG1. Activation of the CTLA-4 pathway reduces immune activity - a general indicator that this therapy has considerable potential for treating RRMS.

3.2.1.2 Studies Following a small pilot study assessing the safety and immune mechanisms of abatacept in 2008 [44], a placebo-controlled, phase II trial was initiated, including 219 patients with RRMS randomized to abatacept at one of two doses or placebo. This trial was prematurely terminated by the safety board because of an increased ARR and inflammatory MRI activity in the lowdose treatment group (NCT00035529) [45]. Although halted prematurely, a post-hoc analysis of the trial revealed that patients in this treatment arm had a higher baseline disease activity at the time of study inclusion, suggesting either a randomization problem or complex dose-response interactions and providing the rationale for another attempt a few years later. In the subsequent placebo-controlled phase II clinical trial, 65 patients with
RRMS were enrolled (ACCLAIM study) [46]. Patients were randomized to monthly intravenous infusions of abatacept or placebo for 24 weeks, with a crossover design at 28 weeks, and received their final dose of study medication at 52 weeks. The pSE, assessing the cumulative number of new GEL, was not reached. No statistically significant differences were observed for other MRI or clinical parameters of disease activity, including alternative endpoints such as no evidence of disease activity (NEDA) [47].

3.2.1.3 Comment Despite its theoretical advantages and proven therapeutic efficacy in some immune-mediated diseases (e.g., RA), CTLA-4-Ig failed to show clinical benefits for other autoimmune conditions, including type 1 diabetes mellitus, lupus nephritis, and RRMS [46, 48]. The ACCLAIM trial had shortcomings in study design. Due to slow enrollment, the investigators decided to close the study earlier than planned after enrolling only 65 patients. Initially, a sample size of 123 patients had been defined to demonstrate a treatment effect of a $50 \%$ reduction in new GEL. Moreover, immunological changes in patients with RRMS participating in the ACCLAIM trial were subsequently analyzed to elucidate the cellular and molecular targets of a co-stimulatory blockade with CTLA-4-Ig [48]. Upon abatacept treatment, a transient decrease in circulating $\mathrm{T}$ follicular helper ( $\mathrm{Tfh}$ ) cells and plasmablasts was observed. The contribution of these cells in the cohort of MS participants from the ACCLAIM trial (RRMS with low disease activity) remains unclear. The observed effects could explain the poor efficacy in this cohort compared with reports on autoimmune conditions strongly associated with aberrant Tfh cell and plasmablast responses [49]. Further, a significant reduction in the relative frequency of $\mathrm{CD} 45 \mathrm{RO}^{+}$memory Treg was detected [48]. These negative effects on Treg cells might impact the balance between effector and regulatory cell function and are detrimental to tolerance induction. This is particularly noteworthy since the frequency of $\mathrm{CD}^{2} 5 \mathrm{RO}^{+}$ memory Treg is limited, and their function is intrinsically impaired in MS [50, 51]. Importantly, despite the observed reduction in Treg cells, no evidence of increased clinical or MRI disease activity was observed following abatacept treatment [46].

Interestingly, the cellular and molecular responses associated with abatacept therapy in both Treg and Tfh cells reversed upon discontinuation of treatment [48]. This reversal indicates that a co-stimulatory blockade does not lead to permanent reprogramming of these cells, providing a further explanation for why abatacept alone does not promote the development of sustained tolerance. 


\subsection{Various mechanisms}

\subsubsection{Vitamin D}

3.3.1.1 Background The complex interplay between environmental risk factors and susceptibility genes that promotes the development of inflammatory brain lesions in MS is still not fully elucidated [52]. Geographical features are one known environmental risk factor. The observed geographical distribution of MS reveals a higher prevalence in regions of higher latitude and lower sunlight exposure. In past years, the immunological relevance of vitamin $\mathrm{D}$ receptor activation has become clearer: activation of vitamin $D$ receptors on $T$ cells induces a shift towards the $T$ helper 2 (Th2) cell lineage, and vitamin D-primed dendritic cells stimulate the expansion of Treg by secreting the antiinflammatory cytokines IL-10 and transforming growth factor (TGF) $\beta$ [53-55]. Of note, a prospective study showed that high circulating levels of vitamin D are associated with a lower risk of MS [56]. Accordingly, a correlation between increased outdoor activities in childhood and adolescence and a reduced risk of developing MS has been reported in several studies $[57,58]$.

3.3.1.2 Studies During the last 5 years, two randomized, placebo-controlled studies (SOLAR, CHOLINE), one dose-escalating study (EVIDIMS), and one related substudy (SOLARIUM) used vitamin D as add-on medication; all these studies failed to meet their pSE [59-61]. In the SOLAR study, 229 RRMS patients who were in a treatment regimen with subcutaneous interferon- $\beta$ - $1 \mathrm{a}$ and had serum vitamin $\mathrm{D}$ levels $<150 \mathrm{nmol} / \mathrm{L}$ were enrolled to receive interferon- $\beta-1$ a plus either placebo or oral high-dose vitamin D 14,007 IU/day [59]. The pSE was the proportion of patients with NEDA-3 (defined as no relapses, no disability progression, and no MRI activity) at week 48 . Thirtysix percent of patients in the active treatment group versus $35.3 \%$ of patients in the placebo group achieved NEDA-3, with no statistically significant difference between groups. SOLARIUM, a substudy of SOLAR, included 56 Dutch participants [60]. The pSE was defined as an increase in the proportion of cells in the immune regulatory cell compartment (Treg and B regulatory cells) at week 48 upon highdose vitamin D supplementation and was not achieved. Also, the proportions of Th subsets were not affected by vitamin $\mathrm{D}$ in this study.

The EVIDIMS trial was a dose-escalating phase II study that enrolled 53 patients with either RRMS or clinically isolated syndrome (CIS) who were under subcutaneous interferon- $\beta-1 b$ treatment [61]. Participants received either high-dose $(20,400 \mathrm{IU})$ or low-dose vitamin D (400 IU) every other day for 18 months. The pSE was based on the
T2-weighted lesion development at month 18 compared with baseline and did not differ between cohorts. The same was observed for further MRI (GEL development, WBA) and clinical outcome measures (ARR, Expanded Disability Status Scale [EDSS] [62] progression).

The CHOLINE trial included 181 RRMS patients on an immunomodulatory therapy with interferon- $\beta-1 \mathrm{a}$, who received either high-dose oral vitamin D3 (100,000 IU) or placebo as an add-on treatment every other week for 2 years [63]. Key inclusion criteria were a low serum vitamin D concentration $(<75 \mathrm{nmol} / \mathrm{L})$ and at least one documented relapse during the previous 2 years. The pSE, defined as a positive change in the ARR at 96 weeks, was not met. However, a significant effect on secondary outcome measures such as a lower volume of T1-weighted lesions and reduced EDSS progression was observed.

3.3.1.3 Comment Although protective effects can be seen in EAE after vitamin D supplementation [53, 54], the relevance in human MS seems to be less conclusive. In this context, the reviewed studies are in line with previous trial failures of oral vitamin D supplementation in MS [64, 65]. The correlation of light exposure, geographical parameters, and vitamin D intake with MS prevalence might be confounded by other factors such as dietary differences and antigen exposure. Moreover, the vitamin D-mediated effect in EAE is thought to be IL-10-dependent [55]. In human MS, this protective effect may be out-scaled by other proinflammatory signaling pathways relevant to MS pathogenesis.

Moreover, a recently published study by Häusler et al. reported clinical deterioration in a murine EAE model upon high-dose vitamin D supplementation, mediated by a T-cell stimulatory effect of secondary hypercalcemia [66]. While vitamin $\mathrm{D}$ at moderate levels exerted a direct regulatory effect, mice with vitamin D levels $>200 \mathrm{nmol} / \mathrm{L}$ developed fulminant EAE with massive CNS infiltration of activated myeloid, Th1, and Th17 cells. Correspondingly, a small pilot study on 15 patients with active RRMS who received vita$\mathrm{min} \mathrm{D}$ at $2.5 \mathrm{mg} /$ day for 48 weeks reported frequent adverse events due to hypercalcemia for patients not strictly adhering to a calcium-restricted diet [67]. In contrast, several highdose vitamin D supplementation studies with median vitamin D levels of up to $380 \mathrm{nmol} / \mathrm{L}$ did not show any cases of hypercalcemia $[59,68,69]$. To this point, no development of proinflammatory $\mathrm{T}$ cells after high-dose vitamin $\mathrm{D}$ supplementation in MS patient cohorts has been described. Therefore, hypercalcemia rather than vitamin D supplements might lead to MS exacerbation. However, mechanistic observations stress the importance of carefully monitoring the calcium metabolism in clinical studies with high-dose vitamin D in MS. Uncritical and continuous supplementation with 
high-dose vitamin $\mathrm{D}$ as propagated by few individuals in the field may not be advisable.

Overall, the studies published to date provide no evidence of a beneficial effect of oral vitamin D supplementation on clinical disease progression in MS.

\subsection{Antiviral Approaches}

Strong evidence suggests that infectious pathogens might trigger the development of MS. In particular, several viruses are associated with the disease and are therefore proposed as treatable therapeutic targets [70]. Viral infections (e.g., human herpes virus, Epstein-Barr virus) often precede the disease onset, and several studies describe viruses as potential triggers of relapse [71, 72]. However, despite great research efforts, no infectious agent has been identified so far that triggers the development of MS.

\subsubsection{Temelimab (GnbAC1)}

3.4.1.1 Background Human endogenous retroviruses (HERVs) represent almost $8 \%$ of the human genome but are usually epigenetically silenced [73, 74]. The expression of HERV-encoded proteins appears to engage pathophysiological pathways, leading to several pathognomonic features of MS, including antibody production and myelin destruction and direct neuropathogenic effects [73, 74]. Interestingly, increased concentrations of the pathogenic HERV Type-W envelope protein (pHERV-W ENV) can be found in the peripheral blood, the CSF and cerebral lesions of MS patients [75] and seems to reflect clinical deterioration [76]. Accordingly, recent experimental studies showed that pHERV-W ENV induces axonal injury and negatively affects remyelination in MS [77].

Temelimab is a humanized IgG4 mAb against the pHERV-W ENV. Preclinical and early-phase safety treatment studies of temelimab indicated good tolerability without signs of immunogenicity, accompanied by the protection of oligodendroglial precursors and decreased levels of proinflammatory cytokine production [78-80].

3.4.1.2 Studies In an early phase II placebo-controlled trial (CHANGE-MS), 270 RRMS patients were randomly assigned to receive either one of three doses of temelimab or placebo [81]. Participants received monthly intravenous infusions of temelimab for 24 weeks. The first results were announced at the ECTRIMS congress in 2017 [82]. The trial failed its pSE, based on the cumulative numbers of GEL in brain MRI over weeks 12-24, for all dosages compared with placebo. Moreover, no significant change in clinically apparent relapses or brain atrophy was observed in the teme- limab patient cohorts. Only in participants showing GEL at baseline, a trend towards a reduction in new GEL was reported for the highest dose of temelimab $(18 \mathrm{mg} / \mathrm{kg})$ versus placebo at the 24-week follow-up. Full publication of this failed trial is still pending.

3.4.1.3 Comment Although some epidemiologic studies suggest that viruses are connected to the development of MS, clinical trials using antiviral agents were mostly negative $[82,83]$. Nevertheless, HERVs are candidates matching many requirements of an 'environmental trigger' for MS development [75, 76, 78]. Abolishing initial or permanent triggers is certainly of value, but adaptive auto- and cross-reactive T- (and B-) cell responses could have already evolved and might promote CNS inflammation independently. Another downside of this approach is that no existing agents are capable of eliminating persisting viruses.

However, while the CHANGE-MS trial revealed no significant immunomodulatory effect on primary clinical and radiological outcomes, non-conventional MRI measures, including magnetization transfer ratio (MTR), were performed as secondary outcome measures. Of note, MTR measures were significantly increased in the patient group receiving high doses of temelimab compared with the placebo cohort. Moreover, cortical and thalamic thinning, as well as the number of $\mathrm{T} 1$ hypointense lesions, were significantly reduced (GeNeuro press release, 2018 [84]). Thus, based on the results, temelimab treatment does not seem to be able to treat the inflammatory-driven part of MS (represented by relapses and GEL lesions); however, the positive outcome on MTR as a marker of remyelination raises awareness of possible neuroprotective effects. Overall, these results should be interpreted with caution since other established DMT have also shown such effects [85, 86].

\subsubsection{Raltegravir}

3.4.2.1 Background The above-mentioned (pre-)clinical and laboratory evidence of the impact of HERVs in MS has been paralleled by clinical observations describing MS-like presentations in patients who were diagnosed with the exogenous retrovirus Human Immunodeficiency Virus (HIV). A few case reports of patients with confirmed diagnoses of both HIV and RRMS demonstrated long-term remission from RRMS when treated with HIV antiretroviral therapy [87]. Therefore, antiretroviral therapy might inhibit HERVs as well as inhibiting HIV, thereby ameliorating MS disease progression. To explore this observation, the phase II INSPIRE trial was conducted, investigating the role of the integrase inhibitor raltegravir in patients with active RRMS [88]. 
3.4.2.2 Studies In the INSPIRE trial, 20 active RRMS patients were enrolled, presenting GEL in the baseline brain MRI within a 3-month observation period without any study medication, followed by a 3-month treatment with raltegravir at $400 \mathrm{mg}$ twice a day. The pSE was the rate of GEL appearing on monthly brain MRI over the treatment period compared with the pretreatment observation time. Raltegravir did not provide statistically significant evidence of efficacy for the primary outcome; neither did it meet secondary outcome measures such as changes in cerebral T2 lesion count, EDSS, the 25-foot timed walk test (25TWT), quantitative virologic measurements, or inflammatory markers.

3.4.2.3 Comment There are a number of possible reasons why raltegravir has no observed efficacy in the INSPIRE trial. First, the reviewed study progressed prematurely to a phase II trial as a previous phase I trial in the respective study population was not conducted. Also, no sufficient preclinical and in vitro data on the effectiveness of antiretroviral therapies in HERVs were available. The dose and frequency of raltegravir were chosen following the licensed regimen for treating HIV infection, and no preceding dosefinding studies were conducted in an MS cohort.

Moreover, the trial was of limited duration, with baseline and treatment phases both comprising 12 weeks. Due to insufficient preliminary data, it is, however, unknown if raltegravir may require longer treatment phases to achieve a therapeutic effect on HERVs. Last, raltegravir was administered as a single therapy and not as a combination of antiretroviral therapies as is effective in treating HIV.

\section{Failed Clinical Trials in Progressive Multiple Sclerosis}

\subsection{B-Cell Targeting Therapies}

\subsubsection{Rituximab}

4.1.1.1 Background The chimeric mouse-human anti$\mathrm{CD} 20 \mathrm{mAb}$ rituximab was the first anti-CD20 antibody to be licensed for use in humans and received an FDA approval for specific malignancies and RA [89]. The CD20 molecule is expressed through $\mathrm{B}$-cell maturation; thus, rituximab effectively depletes late pre-B cells up to and including memory B cells but not early pro-B cells, plasma cells, or plasmablasts [90]. Since 2008, rituximab has received great interest after promising effects were observed in a clinical trial (HERMES) in RRMS patients [10]. However, in 2009, a placebo-controlled phase II/III trial (OLYMPUS) investigating the effect of rituximab on disability progression in PPMS patients failed to meet the pSE [15]. As the underlying cause, it was assumed that the compartmentalization of pathogenic immune responses to CNS tissue in progressive MS prevents access through current DMT [91]. The following phase I/II, placebo-controlled RIVITALISE trial was designed to compare intravenous and intrathecal administration of rituximab versus placebo in patients with SPMS [92].

4.1.1.2 Studies The goal of RIVITALISE was to assess the depletion of B cells in the CNS following both an intravenous and intrathecal induction dose and the impact on neuroinflammation by measuring CSF biomarkers. However, the trial failed to reach the criteria for continuation [92]. Overall, 27 SPMS patients were enrolled in this singlecenter, randomized study, and assigned to receive either rituximab $(n=18)$ or placebo $(n=9)$. Intrathecal rituximab was applied in three single doses of $25 \mathrm{mg}$ each at baseline, 1.5 months, and 12 months. The intravenous induction dose was twice $200 \mathrm{mg}$, with a 15-day interval. Of 18 patients assigned to the treatment group, 14 received at least two doses of intrathecal rituximab and were included in the interim analysis. Clinical evaluations were done every 6 months and included the EDSS, the Scripps Neurological Rating Scale (SNRS) [93], and the MS Functional Composite Scale (MSFC) [94]. Early termination of the trial led to clinical data that was underpowered for reliable analyses, with a maximum follow-up duration of 24 months $(n=5)$. Of note, the interim analysis revealed similar clinical worsening for both placebo and active treatment groups. Correspondingly, the 6-monthly neuroimaging assessment (looking at the cumulative number of GEL) showed no significant results either. CSF and blood samples were collected to quantify the concentrations of selected biomarkers [e.g., rituximab levels, soluble CD21 (sCD21), sCD27, sCD14, BAFF, and CXC motif chemokine 13 (CXCL13)]. Although elevated in both compartments, CSF rituximab levels were approximately 50-fold lower in comparison with serum levels [92]. Consistent with the measurable levels of cell-free rituximab in both compartments, depletion of peripheral B cells was complete and lasting, while the depletion of CSF B cells was incomplete and transient. Accordingly, B cells in CNS tissue were also depleted insufficiently, measured by BAFF levels (as an indirect marker, since BAFF is consumed by B cells and plasma cells). The per-protocol predetermined threshold of at least $50 \%$ increase of BAFF in the CSF was not reached, which was required for study continuation. Moreover, the ratio of sCD21 (a B-cell-specific surface marker, especially on naïve cells) per B cell in the CSF increased significantly at 1.5 months. The ratio of sCD21 is regarded as a measure of B cells compartmentalized to the CNS tissue [95]. Thus, it was concluded that intrathecal rituximab preferentially eliminated the mobile CSF pool of B cells, while CNS tissue-embedded B cells remained unaffected. Furthermore, the second prespecified protocol 
criterion for continuation, a significant decrease in intrathecal CXCL13 levels, was not fulfilled either.

4.1.1.3 Comment Although inflammatory CNS responses also occur in patients with progressive MS forms, DMT proven to be effective in RRMS have largely failed to prevent disability progression in SPMS or PPMS [7, 8, 15, 92, 95, 96]. Lack of therapeutic efficacy in these indications can, in part, be explained by the combination of advanced CNS compartmentalization and terminal differentiation of pathogenic immune responses [97]. Indeed, while immune responses in RRMS patients predominantly consist of cells migrating within the CSF, immune cells in progressive MS patients are mostly embedded in CNS tissue [95]. Tertiary lymphoid follicles and higher levels of terminally differentiated intrathecal lymphocytes apparent in progressive MS as opposed to RRMS further support this concept $[97,98]$. Thus, the rationale behind the RIVITALISE trial is based on the capacity of intravenous rituximab to target systemic and CNS immune cells in RRMS (assuming blood-brain barrier disruption). However, there was no major effect on CSF immune cells and disability in SPMS/PPMS patients (with a more intact blood-brain barrier): combined intravenous and intrathecal rituximab led to lower than expected depletion of intrathecal B cells and limited inhibition of MS-related inflammation in this cohort.

These results are in line with another small phase I trial assessing the safety of intrathecal rituximab in 23 participants with progressive MS and utilizing a similar dosing strategy for intrathecal rituximab as RIVITALISE [99]. Although reaching the primary safety outcome, evaluations of biomarkers revealed no sustained increase in CSF BAFF or reduction in CXCL13 levels, and brain imaging outcomes were unchanged [99]. The low efficacy of rituximab in both trials might be attributed to low bioavailability. Presumably, the intrathecal concentration must be at least as high as serum concentration if rituximab is to reach brain tissue effectively. Whether the intrathecal dose chosen was too low or if complex mechanisms like internalization of the antibody-CD20 complex also play a role in the reduced ability of rituximab to deplete B cells remains elusive [100]. Moreover, a significant efflux of intrathecally administered rituximab into systemic circulation was observed. In the future, the modification of antibody structures (e.g., by minimizing the binding to neonatal Fc-receptor, or by PEGylation) might optimize bioavailability. Moreover, the investigators in the REVITALISE trial attribute the low efficacy, at least in part, to a predominant reduction in complement-induced cytotoxicity after intrathecal rituximab, due to the lack of components capable of assembling the lytic terminal complement complex in the CNS. This assumption is consistent with the observation that supplementation of frozen fresh plasma increases the therapeutic efficacy of rituximab by providing additional complement [101]. However, this approach has not yet been applied to the intrathecal compartment and could have potential side effects on vital CNS tissue.

Nevertheless, two important findings emerge from both trials [92, 99]: (i) administration of antibodies to the CSF seems to be feasible and well tolerated, and (ii) incorporating biomarker assays that measure pharmacodynamic effects on key pathogenic pathways in CNS tissue might be informative for drug development.

\subsection{Primary T-Cell Targeting Therapies}

\subsubsection{Imilecleucel-T (Tcelna/Tovaxin)}

4.2.1.1 Background The T-cell therapy/vaccination (TCV) concept employs an ex vivo enriched source of human myelin reactive $\mathrm{T}$ cells, selected and expanded from each MS donor, attenuated by irradiation, and then re-injected to induce protective immunity $[102,103]$.

The interest in developing an autologous TCV for MS has grown steadily following the observation that murine myelin-reactive T cells can be transferred to induce EAE and that these $\mathrm{T}$ cells can be attenuated by irradiation and used as a vaccine to prevent EAE [104, 105]. Preclinical trials and small studies in humans have supported the hypothesis that TCV improves the clinical MS course through the actions of $\mathrm{CD}^{+}$cytolytic T cells [106]. Also, TCV has been found to elicit Th2 anti-inflammatory regulatory mechanisms, which may contribute to the downregulation of activated Th1/Th17 cells [107]. Small open-label studies of T-cell vaccination revealed that this treatment was well tolerated [106, 108, 109]. However, these promising trends await validation in larger proof-of-principle trials. Imilecleucel-T (Tcelna), formerly known as Tovaxin, is a T-cell immunotherapy that consists of an autologous pool of T-cell lines raised against six immunodominant peptides derived from myelin basic protein (MBP), myelin oligodendrocyte glycoprotein (MOG), and proteolipid protein (PLP) [109].

4.2.1.2 Studies The Abili-T study was designed as a phase II, randomized, placebo-controlled trial, including 183 SPMS patients with recent progression in MS-related neurological deficits. Patients in the Imilecleucel-T study arm received two annual treatment courses consisting of five subcutaneous injections each, over a period of 48 months. In 2016, Opexa Therapeutics announced that the trial did not meet its pSE, defined as a reduction in brain volume change, or secondary study endpoint, defined as reduction in the rate of confirmed disability progression (CDP). Full publication of this failed trial is still pending. 
4.2.1.3 Comment Prior to the conduction of Abili-T, early phase I and II clinical and dose-finding studies on Imilecleucel-T were conducted, indicating that the therapy was safe, well tolerated, and appeared to be associated with clinical benefits [106, 109]. However, trends reported in these pilot studies were not confirmed in the Abili-T trial, suggesting either wrong choices of vaccination clones or the existence of additional important pathophysiological mechanisms unaffected by this approach. Except for a modifying effect on myelin-reactive $\mathrm{T}$ cells, including $\mathrm{CD} 8^{+}$cytotoxic $\mathrm{T}$ cells and $\mathrm{CD} 4{ }^{+} \mathrm{CD} 25^{+} \mathrm{FoxP}^{+}$regulatory $\mathrm{T}$ cells, evidenced by several preclinical trials, it remains elusive whether Imilecleucel-T interacts with other fundamental components of the pathological process in MS such as B cells and participants of the innate immune system. Therefore, the scientific rationale for a vaccination with Imilecleucel-T remains largely theoretical. Moreover, further aspects need to be addressed, such as how long the depletion of reactive $\mathrm{T}$ cells will remain present in the vaccinated individual and if 'boosting' is required. In addition, data from a preceding phase II study of Imilecleucel-T (TERMS) pointed towards a higher efficacy when treatment was administered during the inflammatory phase of RRMS or in DMT-naïve subjects. Since full publication is still pending, no statement about baseline characteristics of the Abili-T trials is available. However, this might further explain the limited treatment efficacy within this cohort.

Of note, further studies are currently investigating TCV in RRMS using peptides from the specific autoantigen-recognizing complementarity determining region of myelinreactive T cells (NeuroVax, Immune Response BioPharma). Preliminary results regarding the vaccine NeuroVax indicate clinical stability in most patients, accompanied by a high frequency of IL-10-secreting cells and an increased expression of Treg cells [110]. Further clinical trials on NeuroVax in pediatric MS (NCT02200718) and SPMS (NCT02057159) are currently ongoing.

\subsection{Blocking or Sequestering Lymphocyte Trafficking}

\subsubsection{Fingolimod}

4.3.1.1 Background Fingolimod, an oral sphingosine 1-phosphate receptor (S1PR) modulator, is effective in treating RRMS [9, 111]. Fingolimod prevents lymphocyte egress from lymphoid tissue into circulation by downregulating the S1P1 receptor subtype. Current evidence further suggests a neuroprotective effect of fingolimod, as it directly reduces astrogliosis, inhibits neurodegeneration, and improves CNS tissue integrity $[112,113]$. Indeed, slowing of whole-brain volume loss has been indicated in three phase III trials on fingolimod in RRMS [9, 114, 115]. The ability of fingoli- mod to reduce inflammatory infiltrates into the CNS while at the same time reducing neurodegeneration provided the rationale for the INFORMS phase III trial in PPMS patients.

4.3.1.2 Studies INFORMS was conducted to assess the safety and efficacy of fingolimod in 970 patients with active PPMS, where active was defined as objective evidence of disability progression during the previous 2 years [7]. Patients were randomly allocated to receive either oral fingolimod ( $1.25 \mathrm{mg} /$ day) or placebo for at least 36 months up to a maximum of 5 years (cohort 1). Following a protocol amendment in November 2009, patients were switched to fingolimod $0.5 \mathrm{mg}$ in a blinded manner, whereas those in the placebo group continued with matching placebo. From then onwards, patients were assigned to receive either fingolimod $(0.5 \mathrm{mg} /$ day) or placebo (cohort 2$)$. The pSE was defined as the time to reach 3 months' sustained reduction in CDP in participants treated for at least 3 years. CDP was assessed based on changes in patients' EDSS scores, walking speed on 25TWT [7], and performance in the 9-hole peg test (9HPT) [116]. The primary efficacy analysis included all patients in cohort 2 and those assigned to placebo in cohort 1. The secondary study endpoint was brain volume loss.

Of note, fingolimod did not slow disease progression in PPMS patients; the secondary study endpoint was also not met.

4.3.1.3 Comment Although a primary composite endpoint was used in the study to improve sensitivity, INFORMS did not show a benefit for fingolimod over placebo.

One key consideration for trials in PPMS patients is whether drugs are more effective in earlier and more active stages of progression or later and less inflammatory stages. In this context, results of the OLYMPUS trial on rituximab in PPMS suggested that age, disease duration, and presence of GEL on brain MRI at baseline could be predictors of therapeutic responsiveness [15]. In the study presented by Lublin and colleagues, more than $40 \%$ of participants were older than 50 years, and only $15 \%$ showed GEL [7]. In contrast, the mean age of the study population in the positive phase III ORATORIO trial on ocrelizumab in PPMS was 44 years, and $26.4 \%$ of participants demonstrated GEL at baseline. Whether the different efficacy ratings between those drugs are a consequence of the study population characteristics or other factors remains unclear $[7,12,117]$.

Moreover, it is unclear whether the duration of contemporary trials in PPMS might be too short to detect efficacy, since the effects of anti-inflammatory therapies may take years to translate into reduced disability [118]. This observation is supported by a randomized, placebo-controlled study of interferon- $\beta-1 \mathrm{~b}$ in progressive MS [119]. At the end of the 2-year study period, no clinical or MRI differences were detected between placebo and active treatment 
arms, whereas after another 5 years without treatment, the interferon- $\beta$ - 1 b-group had significantly better upper limb function and cognitive outcomes. Therefore, even though INFORMS implemented follow-up visits over a period of 3 years, the question arises whether the observation duration was long enough to overcome the therapeutic lag and appropriately assess the efficacy of fingolimod in PPMS.

Lastly, the negative results from INFORMS, combined with results from other trials testing approved RRMS therapies in progressive MS, reinforce the critical insight that knowledge on pathophysiological mechanisms in progressive MS is still limited. There are two aspects to consider in this context: lymphocytes already present in the CNS compartment at initiation might not be affected by S1PR modulation, and fingolimod treatment seems to increase the number of B cells in CSF [120].

\subsubsection{Natalizumab}

4.3.2.1 Background Natalizumab is a recombinant humanized $\mathrm{mAb}$ directed against $\alpha 4$-integrin molecules on leukocytes, blocking transmigration of systemic immune cells into the CNS [121]. This mechanism, and an observed decrease in cerebral microglial activation [121], presented the rationale to test the efficacy of natalizumab in SPMS. Indeed, studies on natalizumab-treated RRMS patients have revealed evidence of enhanced tissue integrity and improved axonal metabolism [122]. Moreover, promising results from early phase I/II studies in SPMS and PPMS indicated suppression of inflammatory CSF biomarkers, axonal damage, and demyelination $[85,123]$ and improved MTR in MRI [85] and ambulation [85, 124] following natalizumab.

4.3.2.2 Studies In light of the aforementioned encouraging data, the phase III ASCEND trial, with an optional 2-year open-label extension, aimed to assess whether natalizumab slows disease progression in 889 subjects with SPMS, independent of relapse rates [8]. Enrolled patients had to show disability progression (measured by an increase in EDSS score) unrelated to the number of relapses in the year before study inclusion. Participants were randomly assigned to receive intravenous natalizumab or placebo for 2 years, or over an extended period covering the extension study. The multicomponent study endpoint was defined as reduced CDP over the 96-week treatment period assessed via EDSS, 25TWT, and 9HPT. Natalizumab showed no treatment effect for the EDSS or 25TWT components. However, it reduced the disability progression of the upper limb component assessed by the 9HPT. Significant reductions in ARR and MRI measures of focal inflammation were also documented.
4.3.2.3 Comment In contrast to several previous trials in progressive MS, ASCEND enrolled patients with predominantly nonrelapsing SPMS $[125,126]$. As it is difficult to detect clinical changes in a slowly progressing MS cohort, ASCEND applied a multicomponent study endpoint. However, two components (EDSS and 25TWT) focused on lower limb function, which is not affected by natalizumab treatment, while statistically significant treatment effects were observed only for upper limb disability progression as measured by the 9HPT. Findings from ASCEND are in line with recent clinical trials on progressive MS that support the length-dependent axonopathy hypothesis [118, 127]. This hypothesis indicates that neuronal domains with longer central axonal projections are more likely to be involved early in the clinically apparent progressive phase of MS. In support, the placebo-controlled trial on oral methotrexate in progressive MS revealed less progression for upper extremity function (9HPT) in the methotrexate group but measured no differences for the lower limb outcomes (EDSS and ambulation scores) [128]. Correspondingly, the IMPACT study, examining intramuscular interferon- $\beta$ - $1 \mathrm{a}$ in SPMS, indicated a significantly reduced MSFC Z-score in the interferon- $\beta-1 \mathrm{a}$-treated subjects [129], an effect driven by the results from the 9HPT and the paced auditory serial addition (PASAT) test, which both assess neuronal domains with shorter axonal pathways. Lessons learned from the aforementioned clinical observations for future trials on progressive MS are (i) requirement of longer treatment phases to capture the potential benefits in all key areas of disability, and (ii) implementation of domain-specific outcome measures that shift the focus to shorter tract-based pathways as well as the importance of adaptive study designs. Overall, a beneficial effect of natalizumab on SPMS disease progression (at least upper limb function) can be assumed.

\subsection{Various Mechanisms}

\subsubsection{MIS416}

4.4.1.1 Background MIS416 is a naturally occurring microparticle formulation derived from the Gram-positive Propionibacterium acnes, which can alter immune responses by interacting with the innate Toll-like receptor 9 (TLR9) and nucleotide-binding oligomerization domaincontaining protein 2 (NOD-2) on myeloid cells. As a result of immune crosstalk under the influence of TLR9-dependent interferon and NOD-2-dependent NFKB signaling, a regulatory and anti-inflammatory immune activity is established [130]. By targeting innate cells, MIS416 reshapes autoimmune T-cell responses, probably resulting in a significant reduction of CNS inflammation. Activation of TLR9 and NOD-2 signaling pathways has profound effects on the Th subset balance by depressing antigen-specific Th1, Th2, and 
Th17 development and leads to an expansion of specific splenic subpopulations including $\mathrm{CD} 4{ }^{+} \mathrm{CD} 25^{+} \mathrm{FoxP} 3^{+}$Treg [131]. These effects coincided with an expansion of specific myeloid subpopulations and increased levels of MIS416stimulated interferon- $\gamma$ and strongly correlated with disease reduction in a model of EAE [131]. Also, immune responses observed in patients after MIS416 administration supported the preclinical results; immune proteins associated with the above-described pathways (e.g., the regulatory immune factors interferon- $\gamma$ and IL-10) transiently increased in SPMS patients [130]. Together, these findings indicate that MIS416 can upregulate myeloid-directed anti-inflammatory pathways, which formed the incentive for a compassionateuse program of MIS416 in patients with SPMS in Australia and New Zealand established prior to early clinical phase I/ II studies [132].

4.4.1.2 Studies Based on positive anecdotal findings from the compassionate-use program and a phase I dose-finding trial in SPMS patients, a subsequent 1-year, phase II, placebo-controlled, randomized trial enrolled 93 patients with SPMS in Australia and New Zealand (NCT02228213). Patients received MIS416 $500 \mu \mathrm{g}$ or placebo intravenously once a week for 52 weeks. Notably, none of the clinical assessments (EDSS, MSFC, PASAT, 9HPT, 25TWT) or MRI measures (T2-lesions, GEL, whole brain atrophy (WBA), MTR) suggested benefits from the myeloid-targeted immune response modifier MIS416 compared with inactive placebo (Immunotherapeutics press release, 2017 [133]). In terms of safety and tolerability, a higher incidence of adverse events in patients taking MIS416 was noted, mainly including fever, chills, and muscle weakness following the induction dose. A full publication of this failed trial is still pending.

4.4.1.3 Comment Although early pre-clinical and human compassionate-use studies showed that MIS416 might improve several myeloid-directed anti-inflammatory pathways by targeting the self-perpetuating innate inflammation within the CNS of progressive MS patients [131], no clinical effect was demonstrated compared with placebo in the phase II trial. Two aspects appear particularly important in this context. First, analysis of the immunological response to MIS416 in a small number of patients showed that patients with less clinical improvement unexpectedly had higher levels of MIS416 plasma biomarkers (e.g., interferon- $\gamma$ and interferon-inducible proteins, NFkB-dependent cytokines IL-6 and IL-10) than those who were ranked as high responders [130]. This result is in contrast to the preclinical results of MIS416 treatment in EAE mice [131]. The observed MIS416 hyper-responsiveness might be explained by the NFKB gene and pathway polymorphisms that have already been described in MS patients and are associated with greater sensitivity to NFkB-activating agents [134]. In line with this assumption, significant inter-patient variation was observed with no clear dose-response relationship in terms of adverse events [132]. Moreover, the use of single TLR9 agonists in EAE demonstrated conflicting results, indicating that TLR9 may play both a protective and detrimental role in EAE $[135,136]$. Whether simultaneous activation of TLR9 and NOD2 by MIS416 induces different signaling pathways, remains elusive.

A second important aspect is that repeated doses of MIS416 resulted in lower biomarker levels than those determined after the first dose, probably reflecting desensitization of MIS416-stimulated immune pathways. Comparable observations have already been described for other agents affecting $\mathrm{NFkB}$ signaling and its respective negative feedback pathway $[130,137]$. Interestingly, this intrinsic regulatory mechanism is further reflected by the diminished severity and frequency of adverse events after repeated doses [132].

\subsubsection{Cyclophosphamide}

4.4.2.1 Background Cyclophosphamide is a nitrogenmustard alkylating agent causing cell death by inter- and intra-strand DNA crosslinking. The more rapidly proliferating cells are more susceptible to cyclophosphamide; thus, bone marrow is disproportionately affected. Cyclophosphamide depletes lymphocytes in both the peripheral blood and CSF [138]. It reduces B and T cells, though preferentially affecting $\mathrm{CD}^{+} \mathrm{T}$ cells [139]. Moreover, cyclophosphamide may shift Th1 towards more favorable Th2 responses [139]. Cyclophosphamide has also been shown to increase interferon- $\gamma$ production of $\mathrm{CD} 8^{+} \mathrm{T}$ cells in patients with SPMS $[139,140]$. Of note, while several studies attributed a prominent proinflammatory function to interferon- $\gamma$, there is also accumulating evidence of a protective role through inducing regulatory cell activity and modulating the effector T-cell response [141]. Altogether, the described findings encouraged the use of cyclophosphamide to target the compartmentalized CNS inflammation in SPMS.

Clinical studies of intravenous cyclophosphamide in progressive MS have given contradictory results [142-144]. The induction regimen with an absence of maintenance therapy could explain the lack of sustained effects [145]. Therefore, monthly administration of cyclophosphamide has been implemented in several centers, and encouraging results regarding efficacy and tolerability have been reported in a large retrospective study [144]. Based on those results, a phase II randomized control trial assessing the efficacy and safety of cyclophosphamide in SPMS patients was conducted (PROMESS).

4.4.2.2 Studies Patients with SPMS were randomized to receive either intravenous cyclophosphamide $(750 \mathrm{mg} /$ 
$\mathrm{m}^{2}$ body surface area) or methylprednisolone $(1000 \mathrm{mg})$, administered every 4 weeks for the first 12 months and every 8 weeks during the second year [146]. Since the inflammatory component is more important in the early stages of SPMS, the population selected for the PROMESS trial was characterized by a recent onset of the progressive phase, with relapses present in $>30 \%$ of patients in the previous year. Due to recruitment difficulties, the study was terminated prematurely after the inclusion of 138 SPMS patients. In the cyclophosphamide group, 33 patients stopped treatment prematurely, mainly due to tolerability issues, compared with 22 patients in the methylprednisolone group. The pSE, defined as a reduction in CDP over 16 weeks, was not reached. However, patients who did not stop treatment with cyclophosphamide prematurely had a 2.7 times less likelihood of disability progression compared with patients who discontinued.

4.4.2.3 Comment One limitation of the PROMESS study is its limited power due to lower patient numbers than planned. The recruitment was poor, and a high proportion of patients stopped treatment and follow-up early, especially in the cyclophosphamide group, which precluded effective assessment of the primary outcome. Interestingly, patients who continued treatment had significantly reduced EDSS progression compared with patients who discontinued (known as 'per-protocol effect'), indicating a benefit of cyclophosphamide in patients who were able to tolerate the treatment.

Another limitation is the use of methylprednisolone as an active comparator [147]. Of note, other recent trials in SPMS populations were mainly placebo-controlled [7, 8, 148]. On the one hand, several methodological strengths emerge from an active comparator design, such as the reduced potential of unmeasured confounding and avoidance of the 'placebo dilemma' in the light of patients' interests and needs. On the other hand, the disadvantages of this design have to be considered when interpreting the results of PROMESS. It is difficult to interpret the relative effect of the drug of interest (in this case cyclophosphamide) compared with an active comparator (methylprednisolone) if the effect of the active comparator drug is unknown. Moreover, it is easier to show a treatment effect, and therefore to claim efficacy to the regulatory authorities in a placebo-controlled setting.

Indeed, the choice of study design in PROMESS is questionable since there was no approved therapy for SPMS available at the time of study initiation, and thus a placebo design might have been justified. How this will be handled in future studies, given that siponimod is now approved as immunomodulatory therapy for SPMS, needs to be determined [148].

Summarizing, although the pSE could not be assessed, secondary analysis suggests a possible effect of cyclophosphamide on disability progression in SPMS patients, but its use may be limited by low tolerability.

\section{Commercial Failure}

We expanded our research to provide a short overview of 'commercial' failures, defined as a compound that met the pSE but failed to progress to a subsequent clinical trial because of pharmaceutical companies' decisions. Of note, all of the following commercial failures relate to phase I studies and are more common than clinical failures in phase I/II in MS research [1]. While most of the reviewed failures revealed promising mechanisms, the companies selected to further develop the agents for treating other autoimmune diseases (e.g., the human antibody to GMCSF otilimab, MOR103, developed by the biotechnology company MorphoSys). Based on preclinical studies in the EAE model [149, 150], a randomized, placebo-controlled, phase I, dose-escalation trial of otilimab determined safety, pharmacokinetics, and immunogenicity in 31 patients with RRMS or SPMS [151], who received either an intravenous infusion of MOR103 or placebo for 10 weeks. The primary objective was safety. MOR103 was generally well tolerated in patients with RRMS or SPMS. No evidence of immunogenicity was found. Despite the positive results of acceptable tolerability, no phase II and III trials have been conducted so far. However, based on company decisions, efforts are ongoing for the further clinical development of otilimab, with a recently enrolled phase III trial in RA (NCT03980483).

Accordingly, a phase I, placebo-controlled trial of inebilizumab (formerly MEDI-551, CD19 ${ }^{+}$B-cell depleting therapy) in 28 RRMS patients led to the further development of this treatment only for neuromyelitis optica spectrum disorder (N-Momentum trial [152]), although revealing an acceptable safety profile and a trend in reducing new $\mathrm{T} 2$ lesions and GEL [27].

Moreover, experimental animal data on ARN-6039 (inverse antagonist of retinoic acid-related orphan nuclear receptor gamma t [ROR $\gamma \mathrm{t}]$, Arrien Pharmaceuticals, NCT03237832) demonstrated a reduction in IL-17 expression and beneficial clinical effects in EAE models. ROR $\gamma \mathrm{t}$ is the key transcription factor driving the differentiation of IL-17 producing Th17 cells implicated in the pathology of MS. Based on the importance of ROR $\gamma t$ in promoting Th17driven pathology, a phase I trial of ARN-6039 in 60 RRMS patients was initiated [153] and results were announced at the 32nd ECTRIMS Congress, demonstrating an excellent safety and tolerability profile [154]. Full publication of this prospective, randomized, placebo-controlled trial is still pending. In 2017, Arrien Pharmaceuticals announced a license agreement for ARN-6039 for treating psoriasis. 
Interestingly, apart from successfully developing a promising agent for disease treatment, the following cell-based SCLERODYM trial (NCT02427776) outlines the great challenges faced by young companies aiming to obtain proofof-concept studies in humans. Cell-based products intended for clinical use need to be manufactured in compliance with current Good Manufacturing Practice regulations. The clinical phase I/II trial SCLERODYM was conducted to assess safety profiles and radiological disease activity in 18 patients with RRMS who received autologous $\mathrm{CD}^{+} \mathrm{T}$ cells that were stimulated and expanded ex vivo. However, in August 2016, ImCyse terminated the trial before enrolling the first patient because of unexpected issues in the manufacturing process.

\section{Expert Commentary}

This review continues and updates previous publications by our group on failed and interrupted MS trials [83, 155-157]. Since it remains extremely difficult to publish negative study results, we here aim to provide an overview of those studies conducted in the last 5 years that are invaluable to our understanding of the pathophysiology and treatment of MS. It should be noted that clinical trials with a focus on neuroprotective strategies and alternative approaches are discussed in a separate article, while this review looks at immunomodulatory strategies.

Of the reviewed trial failures, six trials were completed on patient populations with progressive forms of MS [7, $8,92,133,146,158]$. We noted that the main reason for failed drug development in progressive MS is due to a lack of understanding of the pathophysiology of progression. Although inflammatory mechanisms accompany several neurodegenerative processes and represent the basis for why treatments approved for RRMS have been tested in progressive MS subtypes, studies based on this approach have mainly failed, even when applied directly to the CNS (e.g., REVITALISE) [7, 8, 15, 92, 159]. We have further discovered that limitations in study design often lead to inconclusive and 'failed' trials in SPMS and PPMS. Besides providing a probable benefit for the more active progressive MS study populations (e.g., with GEL, EDSS progression) [7, 12], the trial duration is always an important aspect. Moreover, especially the ASCEND trial [8] highlights that length-dependent MS axonopathy resulting in asynchronous progression should be considered in trial design and interpretation [15, 118, 128, 129]. Therefore, outcome measures should be adapted to detect shorter tract-based pathway functions (e.g., upper limb, visual outcomes).

Also, trial failure was present in RRMS study populations $[16,28,46,59,84,88]$. We could demonstrate that theoretically promising agents may paradoxically increase disease activity-this holds even for those agents that provided positive data or received FDA approval in other inflammatory disorders (e.g., atacicept, abatacept) [28, 46]. In this context, we have further unveiled the complexity of B-cell involvement in MS pathophysiology.

We noted that positive preclinical studies, especially in rodent EAE models, do not guarantee the success of an agent in clinical trials (e.g., vitamin D supplementation). Hence, current animal models are useful tools for developing pharmacological agents but are not able to completely mimic the complexity of human disease. We have further outlined that, interestingly, higher selectivity can imply lower efficacy (e.g., super-selective interventions like TCV). Our observations demonstrate how the availability of pre-clinical in vitro and in vivo data, as well as the completion of a successful and recent phase I trial before the commencement of a phase II trial, may help to mitigate failure risk (e.g., raltegravir) [88]. Finally, the lack of efficacy when applying antiviral strategies further supports the existing doubts on the relevance of viruses in the pathogenesis of MS.

Nonetheless, despite the negative outcomes, all mentioned examples are important studies that add to our growing understanding of MS pathology. Therefore, their publication is indispensable as otherwise precious information may be lost. This review again highlights the need for a debate on current publication policies.

\section{Conclusions}

Clinical trials of new therapeutic agents in MS fail for many different reasons and lessons learned from past and future negative trials are invaluable for our understanding of MS immunopathology and treatment. Therefore, investigators should be strongly encouraged to publish negative or inconclusive results regularly to avoid the loss of relevant information.

The history of reviews published by our group illustrated the ongoing evolution in the field of clinical trials in MS. Firstly, there will always be studies that either fail to demonstrate benefit or are interrupted due to company decisions; an aspect, as already discussed above, of importance to us. Moreover, compared with earlier reviews, the percentage of trials that failed for pathophysiological reasons increased, while the number of studies halted for safety issues decreased. In this context, one of the biggest unmet needs of MS therapy is progression. However, drug development is challenged by the limited understanding of immunology and pathology in progressive MS, where both inflammation and neurodegeneration are contemporarily present in varying degrees at any moment in the course of the disease. 
Therefore, future treatments in progressive MS will probably include an anti-inflammatory approach, which is likely to be combined with myelin repair and neuroprotection. Although the negative results of various agents in progressive MS are disappointing, the reviewed studies provide valuable information. An important lesson herein may be that trial evaluation critically depends on a careful study design and clearly defined patient subgroups. In this respect, the trial design of INFORMS might serve as a model for future trials in progressive MS. In addition, we are hopeful that, given the positive effects of temelimab (GnbAC1) on brain volume loss (although not the primary outcome of the study) and other compounds that address neurodegeneration (e.g., the beneficial effect of natalizumab (at least upper limb function) and cyclophosphamide (although limited by poor tolerability) on disability progression in SPMS patients), further agents will be useful in progressive MS, besides ocrelizumab and siponimod.

Furthermore, failure in one trial does not necessarily mean the failure of an agent in general, as has been shown for natalizumab, fingolimod or cladribine in RRMS patient cohorts in the past. In this regard and given the promising proof-of-concept results of phase I and II trials of imilecleucel-T prior to Abili-T, we shall wait and see whether TCV will be successful in the end.

Finally, one should also keep in mind that some candidates are not developed further, despite some encouraging proof of efficacy (e.g., inebilizumab, ARN-6039). Internal pharmaceutical industry decisions, both economic and political, are causally related to this phenomenon. However, there is always the possibility that the development of these drugs was terminated for clinical reasons not disclosed by the firm.

Acknowledgements Open Access funding provided by Projekt DEAL.

Author Contributions LR: study concept and design, acquisition of data, analysis and interpretation of data, writing of the manuscript. MP: analysis and interpretation of data, writing of the manuscript. SP: study concept and design, critical revision of manuscript for important intellectual content. $\mathrm{NH}$ : critical revision of manuscript for intellectual content. HW: critical revision of manuscript for intellectual content. TR: study concept and design, critical revision of manuscript for intellectual content. SGM: study concept and design, critical revision of manuscript for intellectual content.

\section{Declarations}

Funding No sources of funding were used to assist in the preparation of this review.

Conflict of interest Leoni Rolfes received travel reimbursements from Merck Serono, Sanofi Genzyme, and Roche. Marc Pawlitzki declares no conflicts of interest. Steffen Pfeuffer received travel reimbursements from Sanofi Genzyme and Merck Serono, honoraria for lecturing from Sanofi Genzyme, Biogen, and Mylan Healthcare, and research support from Merck Serono, Diamed, and the German Multiple Sclerosis Society North Rhine-Westphalia. Niklas Huntemann declares no conflicts of interest. Heinz Wiendl received grants from the German Ministry for Education and Research (BMBF), Deutsche Forschungsgesellschaft (DFG), Else Kröner Fresenius Foundation, Fresenius Foundation, the European Union, Hertie Foundation, NRW Ministry of Education and Research, Interdisciplinary Center for Clinical Studies (IZKF) Muenster and RE Children's Foundation, Biogen, GlaxoSmithKline GmbH, Roche Pharma AG, and Sanofi-Genzyme; consulting fees from Abbvie, Actelion, Biogen, IGES, Johnson \& Johnson, Novartis, Roche, and Sanofi-Aventis; support for travel to meetings for other purposes from Abbvie, Actelion, Biogen, IGES, Johnson \& Johnson, Novartis, Roche, and Sanofi-Aventis; fees for participation in review activities such as data monitoring boards from PSI CRO Deutschland $\mathrm{GmbH}$ and Swiss Multiple Sclerosis Society; payment for lectures from Alexion, Biogen, Cognomed, F. Hoffmann-La Roche Ltd., Gemeinnützige Hertie-Stiftung, Merck Serono, Novartis, Roche Pharma AG, Genzyme, TEVA, and WebMD Global; honorarium for expert testimony from Alexion, Biogen, Merck Serono, Novartis, and Genzyme outside the submitted work. He has filed patents No SEP-103.323-1/08, EP2769223, WO2013057092 (A1), and 15001186.4-1402. Tobias Ruck received travel reimbursement and financial research support from Genzyme and Novartis and honoraria for lecturing from Roche, Merck, Genzyme, Biogen, and Teva. Sven G. Meuth received honoraria for lecturing, and travel expenses for attending meetings from Almirall, Amicus Therapeutics Germany, Bayer Health Care, Biogen, Celgene, Diamed, Genzyme, MedDay Pharmaceuticals, Merck Serono, Novartis, Novo Nordisk, ONO Pharma, Roche, Sanofi-Aventis, Chugai Pharma, QuintilesIMS, and Teva. His research is funded by the German Ministry for Education and Research (BMBF), Bundesinstitut für Risikobewertung (BfR), Deutsche Forschungsgemeinschaft (DFG), Else Kröner Fresenius Foundation, Gemeinsamer Bundesausschuss (G-BA), German Academic Exchange Service, Hertie Foundation, Interdisciplinary Center for Clinical Studies (IZKF) Muenster, German Foundation Neurology and Alexion, Almirall, Amicus Therapeutics Germany, Biogen, Diamed, Fresenius Medical Care, Genzyme, HERZ Burgdorf, Merck Serono, Novartis, ONO Pharma, Roche, and Teva.

Availability of data and material Not applicable.

Code availability Not applicable.

Open Access This article is licensed under a Creative Commons Attribution-NonCommercial 4.0 International License, which permits any non-commercial use, sharing, adaptation, distribution and reproduction in any medium or format, as long as you give appropriate credit to the original author(s) and the source, provide a link to the Creative Commons licence, and indicate if changes were made. The images or other third party material in this article are included in the article's Creative Commons licence, unless indicated otherwise in a credit line to the material. If material is not included in the article's Creative Commons licence and your intended use is not permitted by statutory regulation or exceeds the permitted use, you will need to obtain permission directly from the copyright holder. To view a copy of this licence, visit http://creativecommons.org/licenses/by-nc/4.0/.

\section{References}

1. De Gasperis-Brigante CD, Parker JL, O'Connor PW, Bruno TR. Reducing clinical trial risk in multiple sclerosis. Mult Scler Relat Disord. 2016;5:81-8. https://doi.org/10.1016/j.msard .2015.11.007. 
2. Ransohoff RM, Hafler DA, Lucchinetti CF. Multiple sclerosis-a quiet revolution. Nat Rev Neurol. 2015;11(3):134-42. https://doi. org/10.1038/nrneurol.2015.14.

3. Fazekas F, Barkhof F, Filippi M, Grossman RI, Li DK, McDonald WI, et al. The contribution of magnetic resonance imaging to the diagnosis of multiple sclerosis. Neurology. 1999;53(3):44856. https://doi.org/10.1212/wnl.53.3.448.

4. Alvermann S, Hennig C, Stuve O, Wiendl H, Stangel M. Immunophenotyping of cerebrospinal fluid cells in multiple sclerosis: in search of biomarkers. JAMA Neurol. 2014;71(7):905-12. https ://doi.org/10.1001/jamaneurol.2014.395.

5. Weiner HL. Multiple sclerosis is an inflammatory T-cell-mediated autoimmune disease. Arch Neurol. 2004;61(10):1613-5. https://doi.org/10.1001/archneur.61.10.1613.

6. Lucchinetti C, Bruck W, Parisi J, Scheithauer B, Rodriguez M, Lassmann H. Heterogeneity of multiple sclerosis lesions: implications for the pathogenesis of demyelination. Ann Neurol. 2000;47(6):707-17.

7. Lublin F, Miller DH, Freedman MS, Cree BAC, Wolinsky JS, Weiner $\mathrm{H}$, et al. Oral fingolimod in primary progressive multiple sclerosis (INFORMS): a phase 3, randomised, double-blind, placebo-controlled trial. Lancet. 2016;387(10023):1075-84. https://doi.org/10.1016/S0140-6736(15)01314-8.

8. Kapoor R, Ho PR, Campbell N, Chang I, Deykin A, Forrestal $\mathrm{F}$, et al. Effect of natalizumab on disease progression in secondary progressive multiple sclerosis (ASCEND): a phase 3, randomised, double-blind, placebo-controlled trial with an openlabel extension. Lancet Neurol. 2018;17(5):405-15. https://doi. org/10.1016/S1474-4422(18)30069-3.

9. Calabresi PA, Radue EW, Goodin D, Jeffery D, Rammohan KW, Reder AT, et al. Safety and efficacy of fingolimod in patients with relapsing-remitting multiple sclerosis (FREEDOMS II): a double-blind, randomised, placebo-controlled, phase 3 trial. Lancet Neurol. 2014;13(6):545-56. https://doi.org/10.1016/S1474 -4422(14)70049-3.

10. Hauser SL, Waubant E, Arnold DL, Vollmer T, Antel J, Fox $\mathrm{RJ}$, et al. B-cell depletion with rituximab in relapsing-remitting multiple sclerosis. N Engl J Med. 2008;358(7):676-88. https:// doi.org/10.1056/NEJMoa0706383.

11. Perumal J, Fox RJ, Balabanov R, Balcer LJ, Galetta S, Makh $\mathrm{S}$, et al. Outcomes of natalizumab treatment within 3 years of relapsing-remitting multiple sclerosis diagnosis: a prespecified 2-year interim analysis of STRIVE. BMC Neurol. 2019;19(1):116. https://doi.org/10.1186/s12883-019-1337-z.

12. Montalban X, Hauser SL, Kappos L, Arnold DL, Bar-Or A, Comi $\mathrm{G}$, et al. Ocrelizumab versus placebo in primary progressive multiple sclerosis. N Engl J Med. 2017;376(3):209-20. https://doi. org/10.1056/NEJMoa1606468.

13. Giovannoni G, Comi G, Cook S, Rammohan K, Rieckmann $\mathrm{P}$, Soelberg Sorensen $\mathrm{P}$, et al. A placebo-controlled trial of oral cladribine for relapsing multiple sclerosis. N Engl J Med. 2010;362(5):416-26. https://doi.org/10.1056/NEJMoa0902533.

14. Vesterinen HM, Connick P, Irvine CM, Sena ES, Egan KJ, Carmichael GG, et al. Drug repurposing: a systematic approach to evaluate candidate oral neuroprotective interventions for secondary progressive multiple sclerosis. PLoS ONE. 2015;10(4):e0117705. https://doi.org/10.1371/journ al.pone.0117705.

15. Hawker K, O'Connor P, Freedman MS, Calabresi PA, Antel J, Simon J, et al. Rituximab in patients with primary progressive multiple sclerosis: results of a randomized double-blind placebocontrolled multicenter trial. Ann Neurol. 2009;66(4):460-71. https://doi.org/10.1002/ana.21867.

16. Silk M, Nantz E. efficacy and safety of tabalumab in patients with relapsing-remitting multiple sclerosis: a randomized, double-blind, placebo-controlled study (P3.397). Neurology. 2018; 90(15 Suppl).

17. Stettner M, Gross CC, Mausberg AK, Pul R, Junker A, Baba HA, et al. A fatal case of daclizumab-induced liver failure in a patient with MS. Neurol Neuroimmunol Neuroinflamm. 2019;6(2):e539. https://doi.org/10.1212/NXI.0000000000000539.

18. Stork L, Bruck W, von Gottberg P, Pulkowski U, Kirsten F, Glatzel M, et al. Severe meningo-/encephalitis after daclizumab therapy for multiple sclerosis. Mult Scler. 2019;25(12):1618-32. https://doi.org/10.1177/1352458518819098.

19. Rolfes L, Pfeuffer S, Ruck T, Windhagen S, Oschlies I, Pavenstadt HJ, et al. A case of idiopathic multicentric Castleman disease in an alemtuzumab-treated patient with MS. Neurol Neuroimmunol Neuroinflamm. 2020. https://doi.org/10.1212/ NXI.0000000000000638.

20. Esiri MM. Immunoglobulin-containing cells in multiple-sclerosis plaques. Lancet. 1977;2(8036):478.

21. Baker D, Pryce G, Amor S, Giovannoni G, Schmierer K. Learning from other autoimmunities to understand targeting of B cells to control multiple sclerosis. Brain. 2018;141(10):2834-47. https ://doi.org/10.1093/brain/awy239.

22. Monson NL, Cravens PD, Frohman EM, Hawker K, Racke MK. Effect of rituximab on the peripheral blood and cerebrospinal fluid B cells in patients with primary progressive multiple sclerosis. Arch Neurol. 2005;62(2):258-64. https://doi.org/10.1001/ archneur.62.2.258

23. Colombo M, Dono M, Gazzola P, Roncella S, Valetto A, Chiorazzi $\mathrm{N}$, et al. Accumulation of clonally related $\mathrm{B}$ lymphocytes in the cerebrospinal fluid of multiple sclerosis patients. J Immunol. 2000;164(5):2782-9.

24. Constant SL. B lymphocytes as antigen-presenting cells for $\mathrm{CD} 4^{+}$ T cell priming in vivo. J Immunol. 1999;162(10):5695-703.

25. Hauser SL, Bar-Or A, Comi G, Giovannoni G, Hartung HP, Hemmer B, et al. Ocrelizumab versus interferon beta-1a in relapsing multiple sclerosis. N Engl J Med. 2017;376(3):221-34. https:// doi.org/10.1056/NEJMoa1601277.

26. Sorensen PS, Lisby S, Grove R, Derosier F, Shackelford S, Havrdova E, et al. Safety and efficacy of ofatumumab in relapsing-remitting multiple sclerosis: a phase 2 study. Neurology. 2014;82(7):573-81. https://doi.org/10.1212/WNL.0000000000 000125 .

27. Agius MA, Klodowska-Duda G, Maciejowski M, Potemkowski A, Li J, Patra K, et al. Safety and tolerability of inebilizumab (MEDI-551), an anti-CD19 monoclonal antibody, in patients with relapsing forms of multiple sclerosis: results from a phase 1 randomised, placebo-controlled, escalating intravenous and subcutaneous dose study. Mult Scler. 2019;25(2):235-45. https ://doi.org/10.1177/1352458517740641.

28. Kappos L, Hartung HP, Freedman MS, Boyko A, Radu EW, Mikol DD, et al. Atacicept in multiple sclerosis (ATAMS): a randomised, placebo-controlled, double-blind, phase 2 trial. Lancet Neurol. 2014;13(4):353-63. https://doi.org/10.1016/S1474 $-4422(14) 70028-6$.

29. Schneider P. The role of APRIL and BAFF in lymphocyte activation. Curr Opin Immunol. 2005;17(3):282-9. https://doi. org/10.1016/j.coi.2005.04.005.

30. Mabbott NA, Baillie JK, Brown H, Freeman TC, Hume DA. An expression atlas of human primary cells: inference of gene function from coexpression networks. BMC Genomics. 2013;14:632. https://doi.org/10.1186/1471-2164-14-632.

31. Darce JR, Arendt BK, Wu X, Jelinek DF. Regulated expression of BAFF-binding receptors during human B cell differentiation. J Immunol. 2007;179(11):7276-86. https://doi.org/10.4049/jimmu nol.179.11.7276.

32. Sergott RC, Bennett JL, Rieckmann P, Montalban X, Mikol $D$, Freudensprung U, et al. ATON: results from a Phase II 
randomized trial of the B-cell-targeting agent atacicept in patients with optic neuritis. J Neurol Sci. 2015;351(1-2):174-8. https://doi.org/10.1016/j.jns.2015.02.019.

33. Mackay F, Schneider P. TACI, an enigmatic BAFF/APRIL receptor, with new unappreciated biochemical and biological properties. Cytokine Growth Factor Rev. 2008;19(3-4):263-76. https ://doi.org/10.1016/j.cytogfr.2008.04.006.

34. Tak PP, Thurlings RM, Rossier C, Nestorov I, Dimic A, Mircetic $\mathrm{V}$, et al. Atacicept in patients with rheumatoid arthritis: results of a multicenter, phase Ib, double-blind, placebo-controlled, doseescalating, single- and repeated-dose study. Arthritis Rheumatol. 2008;58(1):61-72. https://doi.org/10.1002/art.23178.

35. Rojas OL, Probstel AK, Porfilio EA, Wang AA, Charabati M, Sun T, et al. Recirculating intestinal IgA-producing cells regulate neuroinflammation via IL-10. Cell. 2019;176(3):610-624 e18. https://doi.org/10.1016/j.cell.2018.11.035.

36. Stuve O, Warnke C, Deason K, Stangel M, Kieseier BC, Hartung $\mathrm{HP}$, et al. CD19 as a molecular target in CNS autoimmunity. Acta Neuropathol. 2014;128(2):177-90. https://doi.org/10.1007/s0040 1-014-1313-z.

37. van Vollenhoven RF, Kinnman N, Vincent E, Wax S, Bathon J. Atacicept in patients with rheumatoid arthritis and an inadequate response to methotrexate: results of a phase II, randomized, placebo-controlled trial. Arthritis Rheumatol. 2011;63(7):1782-92. https://doi.org/10.1002/art.30372.

38. Traugott U, Reinherz EL, Raine CS. Multiple sclerosis: distribution of T cell subsets within active chronic lesions. Science. 1983;219(4582):308-10. https://doi.org/10.1126/science.62175 50 .

39. Compston A. The genetics of multiple sclerosis. J Neurovirol. 2000;6(Suppl 2):S5-9.

40. Salomon B, Bluestone JA. Complexities of CD28/B7: CTLA-4 costimulatory pathways in autoimmunity and transplantation. Annu Rev Immunol. 2001;19:225-52. https://doi.org/10.1146/ annurev.immunol.19.1.225.

41. Shevach EM. CD4+ CD25+ suppressor T cells: more questions than answers. Nat Rev Immunol. 2002;2(6):389-400. https://doi. org/10.1038/nri821.

42. Maurer M, Loserth S, Kolb-Maurer A, Ponath A, Wiese $\mathrm{S}$, Kruse N, et al. A polymorphism in the human cytotoxic T-lymphocyte antigen 4 ( CTLA4) gene (exon $1+49$ ) alters T-cell activation. Immunogenetics. 2002;54(1):1-8. https://doi. org/10.1007/s00251-002-0429-9.

43. Ligers A, Xu C, Saarinen S, Hillert J, Olerup O. The CTLA-4 gene is associated with multiple sclerosis. J Neuroimmunol. 1999;97(1-2):182-90. https://doi.org/10.1016/s0165 $-5728(99) 00072-7$.

44. Viglietta V, Bourcier K, Buckle GJ, Healy B, Weiner HL, Hafler DA, et al. CTLA4Ig treatment in patients with multiple sclerosis: an open-label, phase 1 clinical trial. Neurology. 2008;71(12):917-24. https://doi.org/10.1212/01.wnl.00003 25915.00112.61.

45. C. F. A phase II randomised, double-blind, placebo-controlled study to evaluate the preliminary efficacy and safety of abatacept, a selective co- stimulation modulator, in patients with relapsing-remitting multiple sclerosis [abstract no. 0140]. In: 15th Meeting of the European Neurological Society, Vienna; 2005.

46. Khoury SJ, Rochon J, Ding L, Byron M, Ryker K, Tosta P, et al. ACCLAIM: a randomized trial of abatacept (CTLA4Ig) for relapsing-remitting multiple sclerosis. Mult Scler. 2017;23(5):686-95. https://doi.org/10.1177/1352458516662727.

47. Giovannoni G, Turner B, Gnanapavan S, Offiah C, Schmierer K, Marta M. Is it time to target no evident disease activity (NEDA) in multiple sclerosis? Mult Scler Relat Disord. 2015;4(4):32933. https://doi.org/10.1016/j.msard.2015.04.006.
48. Glatigny S, Hollbacher B, Motley SJ, Tan C, Hundhausen C, Buckner JH, et al. Abatacept targets $\mathrm{T}$ follicular helper and regulatory $\mathrm{T}$ cells, disrupting molecular pathways that regulate their proliferation and maintenance. J Immunol. 2019;202(5):137382. https://doi.org/10.4049/jimmunol.1801425.

49. Szentpetery A, Heffernan E, Gogarty M, Mellerick L, McCormack J, Haroon M, et al. Abatacept reduces synovial regulatory T-cell expression in patients with psoriatic arthritis. Arthritis Res Ther. 2017;19(1):158. https://doi.org/10.1186/s1307 5-017-1364-3.

50. Kumar M, Putzki N, Limmroth V, Remus R, Lindemann M, Knop D, et al. CD4+CD25+FoxP3+ T lymphocytes fail to suppress myelin basic protein-induced proliferation in patients with multiple sclerosis. J Neuroimmunol. 2006;180(1-2):178-84. https://doi.org/10.1016/j.jneuroim.2006.08.003.

51. Viglietta V, Baecher-Allan C, Weiner HL, Hafler DA. Loss of functional suppression by CD4+CD25+ regulatory T cells in patients with multiple sclerosis. J Exp Med. 2004;199(7):971-9. https://doi.org/10.1084/jem.20031579.

52. Breuer J, Loser K, Mykicki N, Wiendl H, Schwab N. Does the environment influence multiple sclerosis pathogenesis via UVB light and/or induction of vitamin D? J Neuroimmunol. 2019;329:1-8. https://doi.org/10.1016/j.jneuroim.2018.05.006.

53. Lemire JM, Archer DC. 1,25-dihydroxyvitamin D3 prevents the in vivo induction of murine experimental autoimmune encephalomyelitis. J Clin Investig. 1991;87(3):1103-7. https://doi. org/10.1172/JCI115072.

54. Cantorna MT, Hayes CE, DeLuca HF. 1,25-Dihydroxyvitamin D3 reversibly blocks the progression of relapsing encephalomyelitis, a model of multiple sclerosis. Proc Natl Acad Sci USA. 1996;93(15):7861-4. https://doi.org/10.1073/pnas.93.15.7861.

55. Spach KM, Nashold FE, Dittel BN, Hayes CE. IL-10 signaling is essential for 1,25-dihydroxyvitamin D3-mediated inhibition of experimental autoimmune encephalomyelitis. J Immunol. 2006;177(9):6030-7. https://doi.org/10.4049/jimmu nol.177.9.6030.

56. Munger KL, Levin LI, Hollis BW, Howard NS, Ascherio A. Serum 25-hydroxyvitamin D levels and risk of multiple sclerosis. JAMA. 2006;296(23):2832-8. https://doi.org/10.1001/ jama.296.23.2832.

57. Islam T, Gauderman WJ, Cozen W, Mack TM. Childhood sun exposure influences risk of multiple sclerosis in monozygotic twins. Neurology. 2007;69(4):381-8. https://doi.org/10.1212/01. wnl.0000268266.50850.48.

58. Kampman MT, Wilsgaard T, Mellgren SI. Outdoor activities and diet in childhood and adolescence relate to MS risk above the Arctic Circle. J Neurol. 2007;254(4):471-7. https://doi. org/10.1007/s00415-006-0395-5.

59. Hupperts R, Smolders J, Vieth R, Holmoy T, Marhardt K, Schluep M, et al. Randomized trial of daily high-dose vitamin D3 in patients with RRMS receiving subcutaneous interferon beta-1a. Neurology. 2019;93(20):e1906-e19161916. https://doi. org/10.1212/WNL.0000000000008445.

60. Muris AH, Smolders J, Rolf L, Thewissen M, Hupperts R, Damoiseaux $\mathrm{J}$, et al. Immune regulatory effects of high dose vitamin D3 supplementation in a randomized controlled trial in relapsing remitting multiple sclerosis patients receiving IFNbeta; the SOLARIUM study. J Neuroimmunol. 2016;300:47-56. https ://doi.org/10.1016/j.jneuroim.2016.09.018.

61. Koduah P, Piper SK, Bellmann-Strobl J, Wuerfel J, Paul F, Dörr $\mathrm{J}-\mathrm{M}$. Vitamin D supplementation in multiple sclerosis: primary efficacy endpoint and safety of a randomized, controlled, double-blind phase II trial (EVIDIMS). ECTRIMS Online Library Koduah P Oct 12, 2018; 228159; P1781; 2018. 
62. Kurtzke JF. Rating neurologic impairment in multiple sclerosis: an expanded disability status scale (EDSS). Neurology. 1983;33(11):1444-522.

63. Camu W, Lehert P, Pierrot-Deseilligny C, Hautecoeur P, Besserve A, Jean Deleglise AS, et al. Cholecalciferol in relapsing-remitting MS: a randomized clinical trial (CHOLINE). Neurol Neuroimmunol Neuroinflamm. 2019. https://doi.org/10.1212/ NXI.0000000000000597.

64. Mahon BD, Gordon SA, Cruz J, Cosman F, Cantorna MT. Cytokine profile in patients with multiple sclerosis following vitamin D supplementation. J Neuroimmunol. 2003;134(12):128-32. https://doi.org/10.1016/s0165-5728(02)00396-x.

65. Kimball SM, Ursell MR, O'Connor P, Vieth R. Safety of vitamin D3 in adults with multiple sclerosis. Am J Clin Nutr. 2007;86(3):645-51. https://doi.org/10.1093/ajcn/86.3.645.

66. Häusler D, Torke S, Peelen E, Bertsch T, Djukic M, Nau R, et al. High dose vitamin $\mathrm{D}$ exacerbates central nervous system autoimmunity by raising T-cell excitatory calcium. Brain. 2019;142(9):2737-55. https://doi.org/10.1093/brain/awz190.

67. Wingerchuk DM, Lesaux J, Rice GP, Kremenchutzky M, Ebers GC. A pilot study of oral calcitriol (1,25-dihydroxyvitamin D3) for relapsing-remitting multiple sclerosis. J Neurol Neurosurg Psychiatry. 2005;76(9):1294-6. https://doi.org/10.1136/ jnnp.2004.056499.

68. Rolf L, Damoiseaux J, Huitinga I, Kimenai D, van den Ouweland J, Hupperts R, et al. Stress-axis regulation by vitamin D3 in multiple sclerosis. Front Neurol. 2018;9:263. https://doi.org/10.3389/ fneur.2018.00263.

69. Smolders J, Menheere P, Kessels A, Damoiseaux J, Hupperts R. Association of vitamin D metabolite levels with relapse rate and disability in multiple sclerosis. Mult Scler. 2008;14(9):1220-4. https://doi.org/10.1177/1352458508094399.

70. Moses H Jr, Sriram S. An infectious basis for multiple sclerosis: perspectives on the role of Chlamydiapneumoniae and other agents. BioDrugs. 2001;15(3):199-206. https://doi. org/10.2165/00063030-200115030-00006.

71. Ascherio A, Munger KL, Lennette ET, Spiegelman D, Hernan MA, Olek MJ, et al. Epstein-Barr virus antibodies and risk of multiple sclerosis: a prospective study. JAMA. 2001;286(24):3083-8. https://doi.org/10.1001/jama.286.24.3083.

72. Giovannoni G, Cutter GR, Lunemann J, Martin R, Munz C, Sriram S, et al. Infectious causes of multiple sclerosis. Lancet Neurol. 2006;5(10):887-94. https://doi.org/10.1016/S1474 $-4422(06) 70577-4$

73. Kury P, Nath A, Creange A, Dolei A, Marche P, Gold J, et al. Human endogenous retroviruses in neurological diseases. Trends Mol Med. 2018;24(4):379-94. https://doi.org/10.1016/j.molme d.2018.02.007.

74. Hansen DT, Petersen T, Christensen T. Retroviral envelope proteins: involvement in neuropathogenesis. J Neurol Sci. 2017;380:151-63. https://doi.org/10.1016/j.jns.2017.07.027.

75. Perron H, Germi R, Bernard C, Garcia-Montojo M, Deluen C, Farinelli L, et al. Human endogenous retrovirus type $\mathrm{W}$ envelope expression in blood and brain cells provides new insights into multiple sclerosis disease. Mult Scler. 2012;18(12):1721-36. https://doi.org/10.1177/1352458512441381.

76. Sotgiu S, Mameli G, Serra C, Zarbo IR, Arru G, Dolei A. Multiple sclerosis-associated retrovirus and progressive disability of multiple sclerosis. Mult Scler. 2010;16(10):1248-51. https://doi. org/10.1177/1352458510376956.

77. Kremer D, Forster M, Schichel T, Gottle P, Hartung HP, Perron $\mathrm{H}$, et al. The neutralizing antibody GNbAC1 abrogates HERV-W envelope protein-mediated oligodendroglial maturation blockade. Mult Scler. 2015;21(9):1200-3. https://doi.org/10.1177/13524 58514560926.
78. Kremer D, Gruchot J, Weyers V, Oldemeier L, Gottle P, Healy L, et al. pHERV-W envelope protein fuels microglial cell-dependent damage of myelinated axons in multiple sclerosis. Proc Natl Acad Sci USA. 2019;116(30):15216-25. https://doi.org/10.1073/ pnas. 1901283116.

79. Curtin F, Perron H, Kromminga A, Porchet H, Lang AB. Preclinical and early clinical development of GNbAC1, a humanized $\mathrm{IgG} 4$ monoclonal antibody targeting endogenous retroviral MSRV-Env protein. MAbs. 2015;7(1):265-75. https://doi. org/10.4161/19420862.2014.985021.

80. Derfuss T, Curtin F, Guebelin C, Bridel C, Rasenack M, Matthey A, et al. A phase IIa randomized clinical study testing GNbAC1, a humanized monoclonal antibody against the envelope protein of multiple sclerosis associated endogenous retrovirus in multiple sclerosis patients - a twelve month follow-up. J Neuroimmunol. 2015;285:68-70. https://doi.org/10.1016/j.jneur oim.2015.05.019.

81. Hartung H-P. Week 48 results from a phase IIb trial of GNbAC1 in patients with relapsing remitting multiple sclerosis (CHANGE-MS; clinical trial assessing the HERV-W Env antagonist GNbAC1 for Efficacy in MS). ECTRIMS Online Library Hartung H Oct 11, 2018; 231892; 143; 2018.

82. Kremer D, Kury P, Hartung HP. ECTRIMS/ACTRIMS 2017: closing in on neurorepair in progressive multiple sclerosis. Mult Scler. 2018;24(6):696-700. https://doi.org/10.1177/1352458518 768770 .

83. Ulzheimer JC, Meuth SG, Bittner S, Kleinschnitz C, Kieseier $\mathrm{BC}$, Wiendl H. Therapeutic approaches to multiple sclerosis: an update on failed, interrupted, or inconclusive trials of immunomodulatory treatment strategies. BioDrugs. 2010;24(4):24974. https://doi.org/10.2165/11537160-000000000-00000.

84. GeNeuro. Press release: GeNeuro and Servier announce successful 12-month results in neuroprotection for Phase 2b CHANGEMS Study with GNbAC1 in Multiple Sclerosis. http://www. geneuro.com/data/news/geneuro-pr-positive-12m-results-chang e-ms-en.pdf. Last check: 14.07.2020; 2018.

85. Romme Christensen J, Ratzer R, Bornsen L, Lyksborg M, Garde E, Dyrby TB, et al. Natalizumab in progressive MS: results of an open-label, phase 2A, proof-of-concept trial. Neurology. 2014;82(17):1499-507. https://doi.org/10.1212/WNL.00000 00000000361

86. Arnold DL, Gold R, Kappos L, Bar-Or A, Giovannoni G, Selmaj $\mathrm{K}$, et al. Magnetization transfer ratio in the delayed-release dimethyl fumarate DEFINE study. J Neurol. 2014;261(12):2429-37. https://doi.org/10.1007/s00415-014-7504-7.

87. Maruszak H, Brew BJ, Giovannoni G, Gold J. Could antiretroviral drugs be effective in multiple sclerosis? A case report. Eur J Neurol. 2011;18(9):e110-e11111. https://doi.org/10.111 $1 / \mathrm{j} .1468-1331.2011 .03430 . x$.

88. Gold J, Marta M, Meier UC, Christensen T, Miller D, Altmann $\mathrm{D}$, et al. A phase II baseline versus treatment study to determine the efficacy of raltegravir (Isentress) in preventing progression of relapsing remitting multiple sclerosis as determined by gadolinium-enhanced MRI: The INSPIRE study. Mult Scler Relat Disord. 2018;24:123-8. https://doi.org/10.1016/j.msard 2018.06.002.

89. Edwards JC, Cambridge G, Leandro MJ. B cell depletion therapy in rheumatic disease. Best Pract Res Clin Rheumatol. 2006;20(5):915-28. https://doi.org/10.1016/j.berh.2006.05.010.

90. Maloney DG. Anti-CD20 antibody therapy for B-cell lymphomas. N Engl J Med. 2012;366(21):2008-166. https://doi. org/10.1056/NEJMct1114348.

91. Lehmann-Horn K, Kinzel S, Feldmann L, Radelfahr F, Hemmer $\mathrm{B}$, Traffehn S, et al. Intrathecal anti-CD20 efficiently depletes meningeal B cells in CNS autoimmunity. Ann Clin Transl Neurol. 2014;1(7):490-6. https://doi.org/10.1002/acn3.71. 
92. Komori M, Lin YC, Cortese I, Blake A, Ohayon J, Cherup J, et al. Insufficient disease inhibition by intrathecal rituximab in progressive multiple sclerosis. Ann Clin Transl Neurol. 2016;3(3):166-79. https://doi.org/10.1002/acn3.293.

93. Koziol JA, Lucero A, Sipe JC, Romine JS, Beutler E. Responsiveness of the Scripps neurologic rating scale during a multiple sclerosis clinical trial. Can J Neurol Sci. 1999;26(4):283-9. https ://doi.org/10.1017/s0317167100000391.

94. Cutter GR, Baier ML, Rudick RA, Cookfair DL, Fischer JS, Petkau J, et al. Development of a multiple sclerosis functional composite as a clinical trial outcome measure. Brain. 1999;122(Pt 5):871-82. https://doi.org/10.1093/brain/122.5.871.

95. Komori M, Blake A, Greenwood M, Lin YC, Kosa P, Ghazali D, et al. Cerebrospinal fluid markers reveal intrathecal inflammation in progressive multiple sclerosis. Ann Neurol. 2015;78(1):3-20. https://doi.org/10.1002/ana.24408.

96. Wolinsky JS, Narayana PA, O'Connor P, Coyle PK, Ford C, Johnson K, et al. Glatiramer acetate in primary progressive multiple sclerosis: results of a multinational, multicenter, doubleblind, placebo-controlled trial. Ann Neurol. 2007;61(1):14-24. https://doi.org/10.1002/ana.21079.

97. Correale J, Gaitan MI, Ysrraelit MC, Fiol MP. Progressive multiple sclerosis: from pathogenic mechanisms to treatment. Brain. 2017;140(3):527-46. https://doi.org/10.1093/brain/aww258.

98. Rubenstein JL, Combs D, Rosenberg J, Levy A, McDermott M, Damon L, et al. Rituximab therapy for CNS lymphomas: targeting the leptomeningeal compartment. Blood. 2003;101(2):466-8. https://doi.org/10.1182/blood-2002-06-1636.

99. Bhargava P, Wicken C, Smith MD, Strowd RE, Cortese I, Reich DS, et al. Trial of intrathecal rituximab in progressive multiple sclerosis patients with evidence of leptomeningeal contrast enhancement. Mult Scler Relat Disord. 2019;30:136-40. https:// doi.org/10.1016/j.msard.2019.02.013.

100. Beers SA, French RR, Chan HT, Lim SH, Jarrett TC, Vidal $\mathrm{RM}$, et al. Antigenic modulation limits the efficacy of antiCD20 antibodies: implications for antibody selection. Blood. 2010;115(25):5191-201. https://doi.org/10.1182/blood-2010$01-263533$.

101. Linnoila JJ, Rosenfeld MR, Dalmau J. Neuronal surface antibody-mediated autoimmune encephalitis. Semin Neurol. 2014;34(4):458-66. https://doi.org/10.1055/s-0034-1390394.

102. Medaer R, Stinissen P, Truyen L, Raus J, Zhang J. Depletion of myelin-basic-protein autoreactive $\mathrm{T}$ cells by $\mathrm{T}$-cell vaccination: pilot trial in multiple sclerosis. Lancet. 1995;346(8978):807-8. https://doi.org/10.1016/s0140-6736(95)91622-9.

103. Zhang J, Medaer R, Stinissen P, Hafler D, Raus J. MHC-restricted depletion of human myelin basic protein-reactive $\mathrm{T}$ cells by $\mathrm{T}$ cell vaccination. Science. 1993;261(5127):1451-4. https://doi. org/10.1126/science.7690157.

104. Ben-Nun A, Wekerle H, Cohen IR. The rapid isolation of clonable antigen-specific $\mathrm{T}$ lymphocyte lines capable of mediating autoimmune encephalomyelitis. Eur J Immunol. 1981;11(3):1959. https://doi.org/10.1002/eji.1830110307.

105. Ben-Nun A, Wekerle H, Cohen IR. Vaccination against autoimmune encephalomyelitis with T-lymphocyte line cells reactive against myelin basic protein. Nature. 1981;292(5818):60-1. https ://doi.org/10.1038/292060a0.

106. Loftus B, Newsom B, Montgomery M, Von Gynz-Rekowski $\mathrm{K}$, Riser M, Inman S, et al. Autologous attenuated T-cell vaccine (Tovaxin) dose escalation in multiple sclerosis relapsingremitting and secondary progressive patients nonresponsive to approved immunomodulatory therapies. Clin Immunol. 2009;131(2):202-15. https://doi.org/10.1016/j.clim.2009.01.005.

107. Zang YC, Hong J, Tejada-Simon MV, Li S, Rivera VM, Killian JM, et al. Th2 immune regulation induced by $\mathrm{T}$ cell vaccination in patients with multiple sclerosis. Eur J Immunol.
2000;30(3):908-13. https://doi.org/10.1002/1521-4141(20000 3)30:3<908:AID-IMMU908>3.0.CO;2-1.

108. Karussis D, Shor H, Yachnin J, Lanxner N, Amiel M, Baruch $\mathrm{K}$, et al. $\mathrm{T}$ cell vaccination benefits relapsing progressive multiple sclerosis patients: a randomized, double-blind clinical trial. PLoS ONE. 2012;7(12):e50478. https://doi.org/10.1371/journ al.pone.0050478.

109. Fox E, Wynn D, Cohan S, Rill D, McGuire D, Markowitz C. A randomized clinical trial of autologous T-cell therapy in multiple sclerosis: subset analysis and implications for trial design. Mult Scler. 2012;18(6):843-52. https://doi.org/10.1177/1352458511 428462.

110. Vandenbark AA, Culbertson NE, Bartholomew RM, Huan J, Agotsch M, LaTocha D, et al. Therapeutic vaccination with a trivalent T-cell receptor (TCR) peptide vaccine restores deficient FoxP3 expression and TCR recognition in subjects with multiple sclerosis. Immunology. 2008;123(1):66-78. https://doi.org/10.1 111/j.1365-2567.2007.02703.x.

111. Kappos L, Radue EW, O'Connor P, Polman C, Hohlfeld R, Calabresi $\mathrm{P}$, et al. A placebo-controlled trial of oral fingolimod in relapsing multiple sclerosis. N Engl J Med. 2010;362(5):387401. https://doi.org/10.1056/NEJMoa0909494.

112. Colombo E, Di Dario M, Capitolo E, Chaabane L, Newcombe $\mathrm{J}$, Martino G, et al. Fingolimod may support neuroprotection via blockade of astrocyte nitric oxide. Ann Neurol. 2014;76(3):32537. https://doi.org/10.1002/ana.24217.

113. Foster CA, Mechtcheriakova D, Storch MK, Balatoni B, Howard LM, Bornancin F, et al. FTY720 rescue therapy in the dark agouti rat model of experimental autoimmune encephalomyelitis: expression of central nervous system genes and reversal of bloodbrain-barrier damage. Brain Pathol. 2009;19(2):254-66. https:// doi.org/10.1111/j.1750-3639.2008.00182.x.

114. Cohen JA, Barkhof F, Comi G, Hartung HP, Khatri BO, Montalban X, et al. Oral fingolimod or intramuscular interferon for relapsing multiple sclerosis. N Engl J Med. 2010;362(5):402-15. https://doi.org/10.1056/NEJMoa0907839.

115. Kappos L, Antel J, Comi G, Montalban X, O'Connor P, Polman $\mathrm{CH}$, et al. Oral fingolimod (FTY720) for relapsing multiple sclerosis. N Engl J Med. 2006;355(11):1124-40. https://doi. org/10.1056/NEJMoa052643.

116. Feys P, Lamers I, Francis G, Benedict R, Phillips G, LaRocca N, et al. The Nine-Hole Peg Test as a manual dexterity performance measure for multiple sclerosis. Mult Scler. 2017;23(5):711-20. https://doi.org/10.1177/1352458517690824.

117. Chataway J. Tackling progression in multiple sclerosis. Lancet Neurol. 2018;17(6):489-91. https://doi.org/10.1016/S1474 -4422(18)30158-3.

118. Giovannoni G, Cutter G, Sormani MP, Belachew S, Hyde R, Koendgen $\mathrm{H}$, et al. Is multiple sclerosis a length-dependent central axonopathy? The case for therapeutic lag and the asynchronous progressive MS hypotheses. Mult Scler Relat Disord. 2017;12:70-8. https://doi.org/10.1016/j.msard.2017.01.007.

119. Montalban X, Sastre-Garriga J, Tintore M, Brieva L, Aymerich FX, Rio J, et al. A single-center, randomized, double-blind, placebo-controlled study of interferon beta- $1 \mathrm{~b}$ on primary progressive and transitional multiple sclerosis. Mult Scler. 2009;15(10):1195-205. https://doi.org/10.1177/1352458509 106937.

120. Kowarik MC, Pellkofer HL, Cepok S, Korn T, Kumpfel T, Buck D, et al. Differential effects of fingolimod (FTY720) on immune cells in the CSF and blood of patients with MS. Neurology. 2011;76(14):1214-21. https://doi.org/10.1212/WNL.0b013 e3182143564.

121. Schwab N, Schneider-Hohendorf T, Wiendl H. Therapeutic uses of anti-alpha4-integrin (anti-VLA-4) antibodies in 
multiple sclerosis. Int Immunol. 2015;27(1):47-53. https://doi. org/10.1093/intimm/dxu096.

122. Rudick RA, Stuart WH, Calabresi PA, Confavreux C, Galetta SL, Radue EW, et al. Natalizumab plus interferon beta-1a for relapsing multiple sclerosis. N Engl J Med. 2006;354(9):911-23. https://doi.org/10.1056/NEJMoa044396.

123. Sellebjerg F, Cadavid D, Steiner D, Villar LM, Reynolds R, Mikol D. Exploring potential mechanisms of action of natalizumab in secondary progressive multiple sclerosis. Ther Adv Neurol Disord. 2016;9(1):31-433. https://doi.org/10.1177/17562 85615615257.

124. Cadavid D, Jurgensen S, Lee S. Impact of natalizumab on ambulatory improvement in secondary progressive and disabled relapsing-remitting multiple sclerosis. PLoS ONE. 2013;8(1):e53297. https://doi.org/10.1371/journal.pone.00532 97.

125. Hartung HP, Gonsette R, Konig N, Kwiecinski H, Guseo A, Morrissey SP, et al. Mitoxantrone in progressive multiple sclerosis: a placebo-controlled, double-blind, randomised, multicentre trial. Lancet. 2002;360(9350):2018-25. https://doi.org/10.1016/S0140 -6736(02)12023-X.

126. Panitch H, Miller A, Paty D, Weinshenker B. North American Study Group on Interferon beta-1b in Secondary Progressive MS. Interferon beta- $1 \mathrm{~b}$ in secondary progressive MS: results from a 3-year controlled study. Neurology. 2004;63(10):1788-95. https ://doi.org/10.1212/01.wnl.0000146958.77317.3e.

127. Garbern JY, Yool DA, Moore GJ, Wilds IB, Faulk MW, Klugmann M, et al. Patients lacking the major CNS myelin protein, proteolipid protein 1, develop length-dependent axonal degeneration in the absence of demyelination and inflammation. Brain. 2002;125(Pt 3):551-61. https://doi.org/10.1093/brain/awf043.

128. Goodkin DE, Rudick RA, Van der Brug Medendorp S, Daughtry MM, Schwetz KM, Fischer J, et al. Low-dose (7.5 mg) oral methotrexate reduces the rate of progression in chronic progressive multiple sclerosis. Ann Neurol. 1995;37(1):30-40. https://doi. org/10.1002/ana.410370108.

129. Cohen JA, Cutter GR, Fischer JS, Goodman AD, Heidenreich FR, Kooijmans MF, et al. Benefit of interferon beta-1a on MSFC progression in secondary progressive MS. Neurology. 2002;59(5):679-87. https://doi.org/10.1212/wnl.59.5.679.

130. Webster GA, Sim DA, La Flamme AC, Mayo NE. Evaluation of neurological changes in secondary progressive multiple sclerosis patients treated with immune modulator MIS416: results from a feasibility study. Pilot Feasibility Stud. 2017;3:60. https ://doi.org/10.1186/s40814-017-0201-4.

131. White M, Webster G, O'Sullivan D, Stone S, La Flamme AC. Targeting innate receptors with MIS416 reshapes Th responses and suppresses CNS disease in a mouse model of multiple sclerosis. PLoS ONE. 2014;9(1):e87712. https://doi.org/10.1371/ journal.pone.0087712.

132. Luckey AM, Anderson T, Silverman MH, Webster G. Safety, tolerability and pharmacodynamics of a novel immunomodulator, MIS416, in patients with chronic progressive multiple sclerosis. Mult Scler J Exp Transl Clin. 2015;1:2055217315583385. https://doi.org/10.1177/20552 17315583385 .

133. Society NMS. Results announced from phase 2 trial of MIS416 in secondary progressive MS suggest no benefit. https://www. nationalmssociety.org/About-the-Society/News/Results-Annou nced-from-Phase-2-Trial-of-MIS416-in. Last check: 14.07.2020; 2017.

134. Housley WJ, Fernandez SD, Vera K, Murikinati SR, Grutzendler J, Cuerdon N, et al. Genetic variants associated with autoimmunity drive NFkappaB signaling and responses to inflammatory stimuli. Sci Transl Med. 2015;7(291):291ra93. https://doi. org/10.1126/scitranslmed.aaa9223.
135. Tsunoda I, Tolley ND, Theil DJ, Whitton JL, Kobayashi H, Fujinami RS. Exacerbation of viral and autoimmune animal models for multiple sclerosis by bacterial DNA. Brain Pathol. 1999;9(3):481-93. https://doi.org/10.1111/j.1750-3639.1999. tb00537.x.

136. Boccaccio GL, Mor F, Steinman L. Non-coding plasmid DNA induces IFN-gamma in vivo and suppresses autoimmune encephalomyelitis. Int Immunol. 1999;11(2):289-96. https:// doi.org/10.1093/intimm/11.2.289.

137. Kellogg RA, Tian C, Etzrodt M, Tay S. Cellular decision making by non-integrative processing of TLR inputs. Cell Rep. 2017;19(1):125-35. https://doi.org/10.1016/j.celre p.2017.03.027.

138. ten Berge RJ, van Walbeek HK, Schellekens PT. Evaluation of the immunosuppressive effects of cyclophosphamide in patients with multiple sclerosis. Clin Exp Immunol. 1982;50(3):495-502.

139. Stankiewicz JM, Kolb H, Karni A, Weiner HL. Role of immunosuppressive therapy for the treatment of multiple sclerosis. Neurotherapeutics. 2013;10(1):77-88. https://doi.org/10.1007/ s13311-012-0172-3.

140. Aimard G, Girard PF, Raveau J. Multiple sclerosis and the autoimmunization process Treatment by antimitotics. Lyon Med. 1966;215(6):345-52.

141. Arellano G, Ottum PA, Reyes LI, Burgos PI, Naves R. Stagespecific role of interferon-gamma in experimental autoimmune encephalomyelitis and multiple sclerosis. Front Immunol. 2015;6:492. https://doi.org/10.3389/fimmu.2015.00492.

142. Hauser SL, Dawson DM, Lehrich JR, Beal MF, Kevy SV, Propper RD, et al. Intensive immunosuppression in progressive multiple sclerosis. A randomized, three-arm study of high-dose intravenous cyclophosphamide, plasma exchange, and ACTH. N Engl J Med. 1983;308(4):173-80. https://doi.org/10.1056/ NEJM198301273080401.

143. The Canadian cooperative trial of cyclophosphamide and plasma exchange in progressive multiple sclerosis. The Canadian Cooperative Multiple Sclerosis Study Group. Lancet. 1991;337(8739):441-6.

144. Zephir H, de Seze J, Duhamel A, Debouverie M, Hautecoeur $\mathrm{P}$, Lebrun C, et al. Treatment of progressive forms of multiple sclerosis by cyclophosphamide: a cohort study of 490 patients. J Neurol Sci. 2004;218(1-2):73-7. https://doi.org/10.1016/j. jns.2003.11.004.

145. Weiner HL, Mackin GA, Orav EJ, Hafler DA, Dawson DM, LaPierre Y, et al. Intermittent cyclophosphamide pulse therapy in progressive multiple sclerosis: final report of the Northeast Cooperative Multiple Sclerosis Treatment Group. Neurology. 1993;43(5):910-8. https://doi.org/10.1212/wnl.43.5.910.

146. Brochet B, Deloire MS, Perez P, Loock T, Baschet L, Debouverie $\mathrm{M}$, et al. Double-blind controlled randomized trial of cyclophosphamide versus methylprednisolone in secondary progressive multiple sclerosis. PLoS ONE. 2017;12(1):e0168834. https:// doi.org/10.1371/journal.pone.0168834.

147. Goodkin DE, Kinkel RP, Weinstock-Guttman B, VanderBrugMedendorp S, Secic M, Gogol D, et al. A phase II study of i.v. methylprednisolone in secondary-progressive multiple sclerosis. Neurology. 1998;51(1):239-45. https://doi.org/10.1212/ wnl.51.1.239.

148. Kappos L, Bar-Or A, Cree BAC, Fox RJ, Giovannoni G, Gold $\mathrm{R}$, et al. Siponimod versus placebo in secondary progressive multiple sclerosis (EXPAND): a double-blind, randomised, phase 3 study. Lancet. 2018;391(10127):1263-73. https://doi. org/10.1016/S0140-6736(18)30475-6.

149. King IL, Dickendesher TL, Segal BM. Circulating Ly-6C+ myeloid precursors migrate to the CNS and play a pathogenic role during autoimmune demyelinating disease. Blood. 
2009;113(14):3190-7. https://doi.org/10.1182/blood-2008-07168575 .

150. McQualter JL, Darwiche R, Ewing C, Onuki M, Kay TW, Hamilton JA, et al. Granulocyte macrophage colony-stimulating factor: a new putative therapeutic target in multiple sclerosis. J Exp Med. 2001;194(7):873-82. https://doi.org/10.1084/jem.194.7.873.

151. Constantinescu CS, Asher A, Fryze W, Kozubski W, Wagner F, Aram J, et al. Randomized phase 1b trial of MOR103, a human antibody to GM-CSF, in multiple sclerosis. Neurol Neuroimmunol Neuroinflamm. 2015;2(4):e117. https://doi.org/10.1212/ NXI.0000000000000117.

152. Cree BAC, Bennett JL, Kim HJ, Weinshenker BG, Pittock SJ, Wingerchuk DM, et al. Inebilizumab for the treatment of neuromyelitis optica spectrum disorder (N-MOmentum): a doubleblind, randomised placebo-controlled phase $2 / 3$ trial. Lancet. 2019;394(10206):1352-63. https://doi.org/10.1016/S0140 -6736(19)31817-3.

153. McGinley AM, Edwards SC, Raverdeau M, Mills KHG. Th17cells, gammadelta $\mathrm{T}$ cells and their interplay in EAE and multiple sclerosis. J Autoimmun. 2018. https://doi.org/10.1016/j. jaut.2018.01.001.

154. Rose JW, Carlson NG, Yerramreddy V, Appalanen RP, Handler JA, Kancherla RR, Atiee G, Vankayalapati H. Development of ARN-6039, an ROR $\gamma \mathrm{t} / \mathrm{IL}-17-\mathrm{TH} 17$ specific agent for treatment of multiple sclerosis and evaluation of phase 1 trials in normal controls. ECTRIMS Online Library Rose. 2016;146038:P1610.
155. Pfeuffer S, Ruck T, Kleinschnitz C, Wiendl H, Meuth SG. Failed, interrupted and inconclusive trials on relapsing multiple sclerosis treatment: update 2010-2015. Expert Rev Neurother. 2016;16(6):689-700. https://doi.org/10.1080/14737 175.2016.1176531.

156. Wiendl H, Hohlfeld R. Therapeutic approaches in multiple sclerosis: lessons from failed and interrupted treatment trials. BioDrugs. 2002;16(3):183-200. https://doi.org/10.2165/00063 030-200216030-00003.

157. Meuth SG, Bittner S, Ulzheimer JC, Kleinschnitz C, Kieseier BC, Wiendl $\mathrm{H}$. Therapeutic approaches to multiple sclerosis: an update on failed, interrupted, or inconclusive trials of neuroprotective and alternative treatment strategies. BioDrugs. 2010;24(5):317-30. https://doi.org/10.2165/11537190-000000000-00000.

158. Study of Tcelna (Imilecleucel-T) in secondary progressive multiple sclerosis (Abili-T). ClinicalTrialsgov Identifier: NCT01684761 https://clinicaltrials.gov/ct2/show/NCT0168476 1; 2012-2017.

159. Mahad DH, Trapp BD, Lassmann H. Pathological mechanisms in progressive multiple sclerosis. Lancet Neurol. 2015;14(2):18393. https://doi.org/10.1016/S1474-4422(14)70256-X.

160. Therapeutics O. Opexa Therapeutics press release: Opexa therapeutics announces phase $2 b$ Abili-T Trial of Tcelna ${ }^{\circledR}$ (imilecleucelt) in secondary progressive multiple sclerosis did not meet primary endpoint. https://www.opexatherapeutics.com/files/default_nt5r4 5v4toey75ea2gj6wb.html. Last check: 14.07.2020; 2016. 